\title{
HOXC6 promotes migration, invasion and proliferation of esophageal squamous cell carcinoma cells via modulating expression of genes involved in malignant phenotypes
}

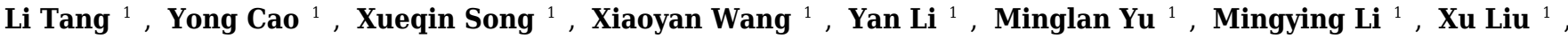 \\ Fang Huang ${ }^{1}$, Feng Chen ${ }^{1}$, Haisu Wan ${ }^{\text {Corresp. }}{ }^{1}$ \\ ${ }^{1}$ Experimental Medicine Center, The Affiliated Hospital of Southwest Medical University, Luzhou, China \\ Corresponding Author: Haisu Wan \\ Email address: whssyzx@swmu.edu.cn
}

Background: HOXC6 is a member of the HOX gene family. The elevated expression of this gene occurs in prostate and breast cancers. However, the role of HOXC6 in esophageal squamous cell carcinoma (ESCC) remains largely uninvestigated.Methods: The expression of HOXC6 was examined by immunohistochemistry, quantitative real-time PCR and immunoblotting assays. The lentivirus-mediated expression of HOXC6 was verified at mRNA and protein levels. Wound healing and Matrigel assays were performed to assess the effect of HOXC6 on the migration and invasion of cancer cells. The growth curving, CCK8, and colony formation assays were utilized to access the proliferation capacities. RNA-seq was performed to evaluate the downstream targets of HOXC6. Bioinformatic tool was used to analyze the gene expression.Results: HOXC6 was highly expressed in ESCC tissues. HOXC6 overexpression promoted the migration, invasion, and proliferation of both Eca109 and TE10 cells. There were 2,155 up-regulated and 759 down-regulated genes in Eca109-HOXC6 cells and 95 up-regulated and 47 down-regulated genes in TE10-HOXC6 cells compared with the results of control. Interestingly, there were only 20 common genes, including 17 up-regulated and 3 down-regulated genes with similar changes upon HOXC6 transfection in both cell lines. HOXC6 activated several crucial genes implicated in the malignant phenotype of cancer cells.Discussion: HOXC6 is highly expressed in ESCC and promotes malignant phenotype of ESCC cells. HOXC6 can be used as a new therapeutic target of ESCC. 
1 HOXC6 promotes migration, invasion and proliferation of esophageal squamous cell

2 carcinoma cells via modulating expression of genes involved in malignant phenotypes

$4 \mathrm{Li}_{\text {Tang}}{ }^{1}$, Yong $\mathrm{Cao}^{1}$, Xueqin Song ${ }^{1}$, Xiaoyan Wang ${ }^{1}$, Yan $\mathrm{Li}^{1}$, Minglan $\mathrm{Yu}^{1}$, Mingying $\mathrm{Li}^{1}, \mathrm{Xu}$

5 Liu ${ }^{1}$, Fang Huang ${ }^{1}$, Feng Chen $^{1} \&$ Haisu Wan ${ }^{1}$

6

71 Experimental Medicine Center, The Affiliated Hospital of Southwest Medical University,

8 Luzhou, Sichuan, China

Corresponding Author:

Haisu Wan ${ }^{1}$

No. 25, Taiping Street, Luzhou, Sichuan, 646000, China.

Email address:whssyzx@swmu.edu.cn

\section{Introduction}

ESCC incidence is the eighth highest, and mortality is the sixth highest, of all cancers worldwide (Cai et al. 2015). Despite the fact that many efforts have been made to improve the diagnosis and therapy of ESCC, the overall 5-year survival rate remains disappointing, and it is still one of the most fatal malignancies (Kashyap et al. 2009; Zhang 2013). The main reason for this is that ESCC is usually in the advanced stages at diagnosis (Kashyap et al. 2009; Zhang 2013). To address this problem, it is necessary to identify potential molecular markers that may be used for the diagnosis and therapy of ESCC.

Homeobox-containing gene family comprises approximately 200 transcription factors which share a 183 base pairs long DNA region called homeobox in their coding sequences, and the homeobox encodes a 61 amino acids homeodomain (HD) with characteristic fold (Cantile et al. 
26 2011). The $H O X$ genes are a subgroup of homeobox-containing genes encoding transcription 27 factors that confer segmental identities in the process of development. In humans, there are 39

28

29

30 31

32 33 34 35

$H O X$ genes clustered into four different groups (HOXA, $H O X B, H O X C$ and $H O X D)$. HOX genes are crucial to the regulation and control of the processes important to development, such as receptor signaling, apoptosis, motility, differentiation, and angiogenesis (Zhang et al. 2013). Many $H O X$ genes have been found to be either activated or repressed in the process of cancer development. Aberrant expression of $H O X$ genes has also been reported in a variety of cancers, such as colorectal (Kanai et al. 2010; Liao et al. 2011), breast (Hur et al. 2014; Shaoqiang et al. 2013), prostate (Chen et al. 2012b), glioblastoma (Costa et al. 2010), and lung (Abe et al. 2006) cancers.

HOXC6 is a member of the $H O X$ family, and its aberrant expression has been verified in a variety of cancers, such as prostate (Ramachandran et al. 2005), breast (Hussain et al. 2015), nasopharyngeal carcinoma (Chang et al. 2017), gastric (Zhang et al. 2013), and ovarian (Tait et al. 2015) cancers. HOXC6 overexpression promoted cell migration, invasion and proliferation, where decreased HOXC6 expression reversed the facilitation effect on gastric cancer cells (Chen et al. 2016). In hepatocellular carcinoma, HOXC6 overexpression promoted cell proliferation, while siRNA-mediated HOXC6 down-regulation not only inhibited proliferation and migration but also increased 5-FU chemosensitivity (Sui et al. 2016). Ji et al (Ji et al. 2016) also found that silencing of HOXC6 expression inhibited the proliferation of colorectal cancer cells. Collectively, these studies suggest that HOXC6 might be involved in tumor initiation and progression. In the case of ESCC, it is predicated that HOXC6 may be highly expressed in ESCC tissues compared to adjacent normal counterparts (Du et al. 2014). However, the role of HOXC6 in ESCC has not been fully investigated. Here we report that HOXC6 functions as an oncogene in ESCC cells via up-regulation of genes associated with the malignant phenotype. HOXC6 is a candidate molecular marker for both the diagnosis and treatment of ESCC.

\section{Materials \& Methods}

Cell lines and cell culture

The ESCC cell lines, Eca109 and TE10, were purchased from the Shanghai Institute of Cell Biology, Chinese Academy of Sciences (Shanghai, China). 293FT cell line was obtained from Shanghai Tongpai biotechnology co. LTD (Shanghai, China). Eca109 and TE10 cells were 
56 cultured in RPMI 1640 medium (Gibco, USA) and 293FT cells was maintained in DMEM

57 (Gibco, USA). All mediums were supplemented with 10\% fetal bovine serum (Gibco, USA), 100

$58 \mathrm{u} / \mathrm{ml}$ of penicillin and $100 \mathrm{u} / \mathrm{ml}$ of streptomycin. All cells were cultured in a $37^{\circ} \mathrm{C}, 5 \% \mathrm{CO}_{2}$

59 incubator.

60 Patients and specimens

61 ESCC tissues and adjacent normal counterpart specimens were obtained from patients with

62 ESCC who were treated with surgery between January 2017 and August 2017 at the Department

63 of Thoracic Surgery, the Affiliated Hospital of Southwest Medical University (Luzhou, China).

64 A portion of each specimen was immediately frozen in liquid nitrogen for qRT-PCR and western

65 blotting assays. Another portion was immediately fixed in neutral formalin buffer and embedded

66 into paraffin for histopathological observation. The present study was approved by the Ethics

67 Committee of the Affiliated Hospital of Southwest Medical University (NO. K2018002-R).

68 Written informed consents for this study were obtained from all patients.

69 RNA extraction and qRT-PCR

70 Total RNA from cells and tissues was extracted with Trizol (Invitrogen; Thermo Fisher

71 Scientific Inc., Waltham, MA, USA) following the manufacturer's instructions. For each

72 specimen, $500 \mathrm{ng}$ of total RNA was used for reverse-transcription using the PrimeScript ${ }^{\mathrm{TM}} \mathrm{RT}$

73 reagent Kit with gDNA Eraser (TaKaRa Bio Inc.). The reaction conditions of reverse-

74 transcription were $15 \mathrm{~min}$ at $37^{\circ} \mathrm{C}$, and $5 \mathrm{sec}$ at $85^{\circ} \mathrm{C}$. qRT-PCR examination was performed

75 using SYBR Premix Ex Taq II (Tli RNaseH Plus) (Thermo Fisher Scientific Inc.). The primer

76 sequences are shown in Table 1. The reaction conditions were as follows: $95^{\circ} \mathrm{C}$ for $30 \mathrm{sec}$,

77 followed by 40 cycles of $95^{\circ} \mathrm{C}$ for $5 \mathrm{sec}$, then $60^{\circ} \mathrm{C}$ for $34 \mathrm{sec}$. Reactions were carried out in an

78 Applied Biosystems 7500 Real Time PCR System (Applied Biosystems, Thermo Fisher

79 Scientific, Inc.). The expression of GAPDH was used as an internal control and the RNA

80 expression level of each gene was evaluated using the $2^{-\Delta \Delta \mathrm{ct}}$ method. All specimens were

81 examined in triplicate.

82 Immunohistochemistry

83 Formalin-fixed paraffin-embedded blocks were prepared into tissue sections. The sections were

84 treated with $3 \% \mathrm{H}_{2} \mathrm{O}_{2}$ for 10 min after routine deparaffinization in xylene and rehydration in

85 decreasing concentrations of ethanol (100, 95, 85 and 75\%). Then, sections were heated in citrate

86 sodium for approximately $3 \mathrm{~min}$ for antigen retrieval. To block nonspecific reactions, the 
87 sections were incubated with 10\% normal goat serum for $20 \mathrm{~min}$ after antigen retrieval. Then,

88 the sections were incubated with a mouse monoclonal antibody against human HOXC6 (Santa

89 Cruz, dilution, 1:200) overnight at $4^{\circ} \mathrm{C}$. After primary antibody incubation, the

90 streptavidin/peroxidase amplification kit (ZSGB-Bio, Beijing, China) was used for the HOXC6

91 antigen-antibody reaction. Then, sections were treated with diaminobenzidine to visualize the

92 appearance of HOXC6 signal. To quantitate the expression of HOXC6, two specialists in

93 pathology independently scored the immunohistochemical signals according to intensity (0-3)

94 and extent (0-100\%). The staining intensity was categorized as follows: 0 , negative (-); 1 , weak

$95(+) ; 2$, moderate $(++)$; and 3, strong $(+++)$. The expression of HOXC6 was calculated as the

96 product of the intensity and extent scores (IHC score).

\section{Western blotting}

98 Lysates of cells and tissues were prepared using pre-cooled RIPA buffer (Cell Signaling,

99 Danvers, MA) supplemented with proteinase inhibitor (Pefabloc SC; Roche, Indianapolis, IN).

100 The total protein concentration was tested using the BCA protein assay kit (ThermoFisher,

101 USA). Total protein lysate $(20 \mu \mathrm{g})$ of each sample was separated using sodium dodecyl sulfate-

102 polyacrylamide gel electrophoresis and then transferred to polyvinylidene difluoride membranes

103 (Millipore, Billerica, MA). Next, the membranes were soaked in 5\% skim milk power to block

104 nonspecific reactions and then incubated with mouse monoclonal antibody against human

105 HOXC6 (Santacruz, dilution, 1:1000) overnight at $4^{\circ} \mathrm{C}$. Membranes were then incubated with the

106 corresponding secondary antibody for $30 \mathrm{~min}$. Immunoreactive protein was visualized using the

107 Western Lighting Chemiluminescence Reagent Plus (Perkin Elmer, Waltham, CA). $\beta$-actin

108 (Santacruz, dilution, 1:1000) was used as internal control.

\section{Establishment of cell lines stably expressing the exogenous HOXC6}

110 The lentiviral HOXC6-expression vector pCDH-HOXC6 was constructed by cloning the human

111 HOXC6 gene into pCDH-NEO vector which is generated by replacing the copGFP gene with

112 genemycin resistance gene of pCDH-CMV-MCS-EF1-copGFP (JiRan, Shanghai, China). The

113 primer sequences including the XhoI and EcoRV restriction enzyme sites are shown in Table 2.

114 The lentiviral particles were produced by transfecting either pCDH-HOXC6 or pCDH-NEO with

115 psPAX2 and pMD2.G into 293FT cells. The culture supernatant was harvested and subsequently

116 infected Eca109 and TE10 cells. The stable cells were selected by genemycin at a concentration

117 of $500 \mu \mathrm{g} / \mathrm{ml}$ (ThermoFisher). 
118 Wound healing and Matrigel invasion assay

119 Cells were seeded in 96-well plates and allowed to achieve 90\%-100\% confluence. The Essen

120 Bioscience 96-pin wound maker (Essen BioScience, Ann Arbor, MI) was used to create a

121 uniform scratch in each well. For the wound healing assay, cells were incubated in RPMI 1640

122 medium supplemented with $2 \%$ fetal bovine serum. For the invasion assay, cells were covered

123 with $50 \mu$ l of Matrigel solution ( $2.4 \mathrm{mg} / \mathrm{ml}$ Matrigel in normal growth medium, BD Biosciences)

124 that was allowed to gel at $37^{\circ} \mathrm{C}$ for $1 \mathrm{~h}$. Then, an additional $100 \mu \mathrm{l} /$ well of normal growth

125 medium was used to overlay the matrix. The wound of each well was monitored and images

126 were taken at $2 \mathrm{~h}$ intervals in an IncuCyte live-cell analysis system (Essen BioScience, Ann

127 Arbor, MI). The wound width was calculated using the software provided.

128 Growth, CCK8, and colony formation assays

129 Cells were plated in 96-well plates (3000 cells/well). Cell growth was monitored and images

130 were taken at $2 \mathrm{~h}$ intervals in an IncuCyte live-cell analysis system. Growth curves were

131 calculated from confluence measurements using image analysis software. For the Cell Counting

132 Kit-8 assay (Dojindo Molecular Technologies, Inc., Kumamoto, Japan), optical density was

133 measured to determine cell activity at a wavelength of $450 \mathrm{~nm}$ on a microplate reader at $0,24,48$

134 and 72h. For the colony formation assay, stably infected cells were seeded in 6-well plates (200

135 cells/well) and the growth medium was changed at 3-day intervals. After 10 days of incubation at

$13637^{\circ} \mathrm{C}$ with $5 \% \mathrm{CO}_{2}$, cells were fixed with $4 \%$ paraformaldehyde and stained with freshly

137 prepared, diluted Giemsa stain for $20 \mathrm{~min}$. Colony number was counted after excess dye was

138 washed off with double-distilled water.

139 RNA-seq analysis

140 Total RNA was isolated with Trizol and the polyadenylated mRNAs were enriched using

141 Dynabeads Oligo (dT) 25 beads. Three replicates were created for RNA-seq library construction

142 using the NEBNext Ultra Directional RNA Library Prep Kit for Illumina (NEB), following the

143 manufacturer's instructions. Illumina HiSeq Xten was used to perform $150 \mathrm{bp}$ pair-end

144 sequencing. We mapped all RNA-seq data to the GRCh37.p13 genome from GENCODE

145 (Harrow et al. 2012) by HISAT2 (version 2.1.0)(Kim et al. 2015) with default parameters. To

146 identify differentially expressed genes (DEGs), we aggregated the read counts at the gene level

147 using HTseq (Anders et al. 2015), and then identified DEGs using R package DESeq2(Love et

148 al. 2014). Genes were considered significantly differentially expressed when the $\mid \log _{2}$ (fold- 
149 change $) \mid>1$ and adjusted $\mathrm{p}<0.05$. DEGs were subjected to enriched GO categorization using 150 the R package clusterProfiler (Yu et al. 2012) with a q-value $<0.05$.

\section{Bioinformatic analysis}

152 Gene Expression Omnibus (GEO) is a public functional genomics data repository supporting 153 MIAME-compliant data submissions. We utilized this tool to investigate gene expression. GEO 154 is available at https://www.ncbi.nlm.nih.gov/geo/.

\section{Statistical analysis}

156 All experimental data are presented as the mean \pm standard deviation from 2 to 3 separate 157 experiments. Wound healing Matrigel invasion and growth curve assays were conducted in at least 15812 repeats for every separate experiment. CCK8 and colony formation assays were conducted in 159 triplicate. Data was analyzed using SPSS19.0 software. Comparisons between groups were 160 performed using Student's $t$ test, and differences were considered statistically significant at $\mathrm{p}<$ 1610.05.

\section{Results}

\section{HOXC6 was highly expressed in ESCC tissues}

164 HOXC6 is highly expressed in many cancer types (Fig. 1A-1I), including ESCC (Fig. 1G -1I).

165 This suggests that HOXC6 may be a critical factor in cancer development. However, the role of 166 this gene in ESCC is not clear. We investigated the expression of HOXC6 in ESCC cells. We 167 first investigated the expression of HOXC6 using clinical tumor samples. Thirty-two paired 168 samples from patients that underwent ESCC resection were used to verify the expression of 169 HOXC6 by IHC and qRT-PCR. Representative images of the HOXC6 IHC assays are shown in 170 Fig. 2A. The IHC score of HOXC6 in tumor tissues was significantly higher than in adjacent 171 normal counterparts (Fig. 2B). The relative HOXC6 mRNA expression level in tumor tissues was 172 also significantly higher than in adjacent normal counterparts (Fig. 2C). We randomly selected 173 three paired samples to analyze the expression level of the HOXC6 protein by western blotting, 174 and the results showed that HOXC6 in tumor tissues was highly expressed when compared with 175 adjacent normal counterparts (Fig. 2D-2E). These results suggest that HOXC6 expression may 176 play a role in the malignancy of ESCC.

\section{HOXC6 promoted ESCC cell migration and invasion}


178 To explore how HOXC6 affects the malignant phenotype of ESCC cells, we introduced the 179 HOXC6 gene into Eca109 and TE-10 cells via lentiviral-mediated transfection, generating cell 180 lines stably expressing HOXC6 (Eca109-HOXC6 and TE10-HOXC6) as well as cell lines 181 transfected with empty vector (Eca109-NEO and TE10-NEO). Fig. 3A shows the lentiviral 182 vector pCDH-HOXC6. The expression level of HOXC6 was confirmed by both qRT-PCR (Fig. 183 3B), western blotting (Fig. 3C-3D) and immunocytochemistry assay (Fig. 3E). Since the 184 migration and invasion of tumor cells is critical for tumor angiogenesis and metastasis, we 185 assessed the effect of HOXC6 on ESCC cell migration and invasion using wound healing and 186 Matrigel invasion assays. By calculating wound healing width and invasion width of the scratch 187 wound, we found that HOXC6 overexpression significantly increased cell migration speed in 188 Eca109-HOXC6 and TE10-HOXC6 cells compared to controls (Fig. 4A-4D). The Matrigel 189 invasion assay demonstrated that HOXC6 significantly improved the invasive capacity of the 190 ESCC cells (Fig. 5A-5D). These results suggest that HOXC6 may act as a facilitator in 191 promoting ESCC cell migration and invasion.

\section{HOXC6 promoted ESCC cell proliferation}

193 To assess the effect of HOXC6 on ESCC cell proliferation, we utilized a real-time monitoring assay to measure the growth rates of Eca109-HOXC6 and TE10-HOXC6 as well as their controls. Growth curves were constructed from data points acquired at $2 \mathrm{~h}$ intervals. Results showed that the growth of Eca109-HOXC6 and TE10-HOXC6 was significantly faster than that of controls (Fig. 6A-6B). Furthermore, CCK8 and colony formation assays were also performed. The OD450 values of Eca109-HOXC6 and TE10-HOXC6 were higher than that of controls when measured after 72 hours (Fig. 6C-6D). In addition, the results of the colony formation assay showed that Eca109-HOXC6 and TE10-HOXC6 generated more colonies than the controls

201 (Fig. 6E-6F). Collectively, these results suggest that HOXC6 may increase the proliferation and 202 colony formation of ESCC cells.

203

204

205

206 207 208

\section{RNA-seq analysis identified genes regulated by $\mathrm{HOXC6}$}

As a member of the homeobox gene family, HOXC6 possesses the characteristics of a transcription factor that can bind to a specific sequence in the genome and regulate the expression of related genes. To identify the downstream targets and the regulatory network of HOXC6, RNA-seq was conducted to compare changes of mRNA expression patterns following HOXC6 transfection. The raw RNA-seq data in this article has been uploaded to Gene Expression 
209 Omnibus (GEO) repository and the accession number is GSE121976. The expression levels of 210 individual genes were measured by sequence counts. Genes with at least a two-fold change in 211 expression were viewed as either up-regulated or down-regulated genes. The global changes in 212 mRNA expression patterns are shown in Fig. 7A for Eca109-HOXC6 and TE10-HOXC6. As 213 shown in Fig. 7B, there were 2,155 up-regulated and 759 down-regulated genes in Eca109214 HOXC6 cells compared with Eca109-NEO cells. In addition, there were 95 up-regulated and 47 215 down-regulated genes in TE10-HOXC6 cells compared with TE10-neo cells. Interestingly, there 216 were only 20 common genes, including 17 up-regulated and 3 down-regulated genes with similar 217 changes upon HOXC6 transfection in both cell lines (Fig. 7C), indicating the cell-context 218 dependent function of HOXC6 in different cell lines. The common regulated genes are shown in 219 Figure 7C in the format of a table. There are 14 common upregulated genes, many of these genes 220 have been reported to be implicated in the development of various types of cancers. There are

221

222 223 224 225 226 227 228 229 230 231 232 233 234 235 236 237 238 239 also 3 common downregulated genes, however, the function of these genes has not been well characterized. We further confirmed the results of RNA-seq by examining the expression of HOXC6-modulated genes using qRT-PCR. As shown in Fig. 7D-7E, changes in expression level of these genes were consistent with the RNA-seq results.

\section{HOXC6 upregulated critical genes involved in malignant phenotype}

To understand the mechanism underlying the function of $H O X C 6$, we investigated the downstream targets identified by RNA-seq. As demonstrated by GO analysis (Fig. 7F-7G), the genes regulated by HOXC6 could be categorized into various functional groups, including organelle fission and nuclear division in Eca109-HOXC6 cells, and angiogenesis and tRNA aminoacylation for protein translation in TE10-HOXC6 cells. Functional pathway analysis (Fig. 7H-7I) suggested that HOXC6 may have functions mediated by crosstalk with important signaling pathways such as p53 and focal adhesion in Eca109-HOXC6 cells, and the TGF- $\beta$ signaling pathway and aminoacyl-tRNA biosynthesis in TE10-HOXC6 cells. These analyses indicate that $H O X C 6$ executed its function via distinct mechanisms in various cell lines. However, these results failed to provide clear clues to how HOXC6 affects the malignant phenotype of cells. We then investigated the genes up-regulated in both Eca109-HOXC6 and TE10-HOXC6 cells. Interestingly, as indicated in Table 3, there were many genes involved in the malignant phenotype of various cancers. Furthermore, as demonstrated by bioinformatic analysis (Fig. 8), some of the genes up-regulated by HOXC6 were highly expressed in ESCC. In 
240 the present study, HOXC6 further upregulated the expression of these genes. This evidence

241 suggests that HOXC6 may execute its function via activating the expression of genes involved in 242 malignant phenotype.

\section{Discussion}

244 Tumor development is often associated with the abnormal expression of critical genes (Hanahan 245 \& Weinberg 2011; Wang et al. 2013). HOXC6 belongs to the HOX gene family and encodes HD246 containing transcription factors with the capacity to bind specific DNA sequences and regulate 247 the expression of downstream genes (Hussain et al. 2015). The aberrant expression of HOXC6 248 has been reported in many cancer types; however, the mechanisms underlying the function of 249 this gene in cancer cells have not been fully elucidated. We explored the role of HOXC6 in the 250 251 malignant phenotype of ESCC. Based on our results, the expression of HOXC6 was significantly elevated in ESCC cells. In addition, ectopic expression of HOXC6 promoted the migration, invasion, and proliferation of ESCC cells. Since these phenotypes are directly related to the development and progression of cancer, HOXC6 emerges as an oncogene in ESCC. This is

254 255 consistent with the results of other reports focused on the function of $\mathrm{HOXC6}$ in cancers other than ESCC.

Like other HD proteins, HOXC6 may execute its effects via binding to specific sequences in the genome following HOXC6 transfection. However, to our surprise, we found that HOXC6 exerted its effects on the transcription patterns of cancer in a cell-context-dependent manner. HOXC6 modulated distinct sets of genes in different ESCC cell lines. This may result from the fact that the specificity of an HD protein usually requires the formation of various complexes, and the availability of other cofactors may be critical for the modulation of downstream targets (Ladam $\&$ Sagerstrom 2014). Many factors have been identified as interacting partners of homeoboxcontaining gene products. For example, these factors may interact with other members of the HD protein family, chromatin remodeling factors, or other transcription factors (Ladam \& Sagerstrom 2014). The function of an HD protein may be influenced by both the expression level and the modification status of these interacting partners.

To determine the mechanisms underlying the oncogenic function of HOXC6, we compared the genes that were up-regulated in Eca109-HOXC6 and TE10-HOXC6 cells. Results showed that both of these cell lines contain genes with unambiguous functions that are associated with the malignant phenotype in various types of cancers. These genes included MMP14, SPARC, and 
271 FN1. MMP14 is a member of the matrix metalloproteinase (MMP) family, which can degrade 272 collagen and other extracellular matrix proteins (Ulasov et al. 2014). MMP14 not only promotes 273 cell migration, invasion, and angiogenesis in nasopharyngeal carcinoma (Yan et al. 2015) and 274 pituitary adenomas (Hui et al. 2015) but also promotes the secretion of pro-MMP2 and pro275 MMP9 (Zarrabi et al. 2011). SPARC is a collagen-binding glycoprotein that interacts with 276 MMPs and growth factors, such as TGF- $\beta$ and fibroblast growth factor (Vaz et al. 2015). SPARC 277 can enhance cell invasion, metastasis, and growth while inducing apoptosis in gastric (Yin et al. 278 2010) and ovarian (Chen et al. 2012a) cancers. FN1 can induce abnormal expression of some 279 MMPs, such as MMP9/MMP2 (Moroz et al. 2013; Qian et al. 2011) and promote proliferation, 280 migration, and invasion in thyroid(Sponziello et al. 2016) and gastric (Zhang et al. 2017) 281 cancers. In addition, $A K A P 9$, SATB 1, SEMA3C, SGK1, and INHBA etc have also been reported 282 to enhance cell migration, invasion, proliferation and angiogenesis or induce apoptosis in various 283 cancers, such as pancreatic (Chen et al. 2015; Xu et al. 2017), glioma (Hulleman et al. 2009; 284 Man et al. 2014; Senft et al. 2011), breast (Han et al. 2008; Malik et al. 2016), lung (Seder et al. 285 2009b), esophageal (Seder et al. 2009a), prostate (Mao et al. 2013), and colorectal (Hu et al. 286 2016; Lang et al. 2010; Liang et al. 2017; Yang et al. 2015; Zheng \& Yu 2018), cutaneous 287 squamous cell carcinoma(Riihila et al. 2014), liver(Seol et al. 2016), cervical(Luo et al. 2016), 288 gastric(Yuan et al. 2013) and osteosarcoma(Tsuru et al. 2015) cancers.

289 In conclusion, HOXC6 promoted ESCC cell migration, invasion, and proliferation, and its 290 function may be related to the aberrant expression of genes caused by HOXC6 overexpression. 291 HOXC6 may be a new significant biomarker for diagnosis, therapy, and prognosis. Targeted 292 inhibition of HOXC6 may be a new strategy for the treatment of ESCC. However, the precise 293 molecular mechanism is not completely understood, and further investigation is still needed.

\section{Conclusion}

295 HOXC6 promoted the malignant phenotypes of ESCC cells. HOXC6 could activate the 296 expression of oncogenic genes in a cell context-dependent manner. Targeted inhibition of 297 HOXC6 might provide a new strategy for the therapy of ESCC.

\section{Acknowledgements}

299 We offer many thanks to all colleagues for their contribution to this study.

\section{References}


301

302

303

304

305

306

307

308

309

310

311

312

313

314

315

316

317

318

319

320

321

322

323

324

325

326

327

328

329

330

331

332

333

334

335

336

337

338

339

340

341

342

343

344

345

346

347

348

349

350
Abe M, Hamada J, Takahashi O, Takahashi Y, Tada M, Miyamoto M, Morikawa T, Kondo S, and Moriuchi T. 2006. Disordered expression of HOX genes in human non-small cell lung cancer. Oncol Rep 15:797-802.

Anders S, Pyl PT, and Huber W. 2015. HTSeq--a Python framework to work with highthroughput sequencing data. Bioinformatics 31:166-169. 10.1093/bioinformatics/btu638

Cai HX, Zhu ZQ, Sun XM, Li ZR, Chen YB, and Dong GK. 2015. Gene expression profile of human esophageal squamous carcinoma cell line TE-1. Int J Clin Exp Med 8:1426814276.

Cantile M, Franco R, Schiavo G, Procino A, Cindolo L, Botti G, and Cillo C. 2011. The HOX genes network in uro-genital cancers: mechanisms and potential therapeutic implications. Curr Med Chem 18:4872-4884.

Chang SL, Chan TC, Chen TJ, Lee SW, Lin LC, and Win KT. 2017. HOXC6 Overexpression Is Associated With Ki-67 Expression and Poor Survival in NPC Patients. J Cancer 8:16471654. 10.7150/jca. 18893

Chen J, Wang M, Xi B, Xue J, He D, Zhang J, and Zhao Y. 2012a. SPARC is a key regulator of proliferation, apoptosis and invasion in human ovarian cancer. PLoS One 7:e42413. 10.1371/journal.pone.0042413

Chen JL, Li J, Kiriluk KJ, Rosen AM, Paner GP, Antic T, Lussier YA, and Vander Griend DJ. 2012b. Deregulation of a Hox protein regulatory network spanning prostate cancer initiation and progression. Clin Cancer Res 18:4291-4302. 10.1158/1078-0432.CCR-120373

Chen SW, Zhang Q, Xu ZF, Wang HP, Shi Y, Xu F, Zhang WJ, Wang P, and Li Y. 2016. HOXC6 promotes gastric cancer cell invasion by upregulating the expression of MMP9. Mol Med Rep 14:3261-3268. 10.3892/mmr.2016.5640

Chen Z, Li Z, Li W, Zong Y, Zhu Y, Miao Y, and Xu Z. 2015. SATB1 Promotes Pancreatic Cancer Growth and Invasion Depending on MYC Activation. Dig Dis Sci 60:3304-3317. 10.1007/s10620-015-3759-9

Costa BM, Smith JS, Chen Y, Chen J, Phillips HS, Aldape KD, Zardo G, Nigro J, James CD, Fridlyand J, Reis RM, and Costello JF. 2010. Reversing HOXA9 oncogene activation by PI3K inhibition: epigenetic mechanism and prognostic significance in human glioblastoma. Cancer Res 70:453-462. 10.1158/0008-5472.CAN-09-2189

Du YB, Dong B, Shen LY, Yan WP, Dai L, Xiong HC, Liang Z, Kang XZ, Qin B, and Chen KN. 2014. The survival predictive significance of $\mathrm{HOXC6}$ and HOXC8 in esophageal squamous cell carcinoma. J Surg Res 188:442-450. 10.1016/j.jss.2014.01.017

Han HJ, Russo J, Kohwi Y, and Kohwi-Shigematsu T. 2008. SATB1 reprogrammes gene expression to promote breast tumour growth and metastasis. Nature 452:187-193. 10.1038/nature06781

Hanahan D, and Weinberg RA. 2011. Hallmarks of cancer: the next generation. Cell 144:646674. 10.1016/j.cell.2011.02.013

Harrow J, Frankish A, Gonzalez JM, Tapanari E, Diekhans M, Kokocinski F, Aken BL, Barrell D, Zadissa A, Searle S, Barnes I, Bignell A, Boychenko V, Hunt T, Kay M, Mukherjee G, Rajan J, Despacio-Reyes G, Saunders G, Steward C, Harte R, Lin M, Howald C, Tanzer A, Derrien T, Chrast J, Walters N, Balasubramanian S, Pei B, Tress M, Rodriguez JM, Ezkurdia I, van Baren J, Brent M, Haussler D, Kellis M, Valencia A, Reymond A, Gerstein M, Guigo R, and Hubbard TJ. 2012. GENCODE: the reference human genome annotation for The ENCODE Project. Genome Res 22:1760-1774. 10.1101/gr.135350.111

Hu ZY, Liu YP, Xie LY, Wang XY, Yang F, Chen SY, and Li ZG. 2016. AKAP-9 promotes colorectal cancer development by regulating Cdc42 interacting protein 4. Biochim Biophys Acta 1862:1172-1181. 10.1016/j.bbadis.2016.03.012 
351

352

353

354

355

356

357

358

359

360

361

362

363

364

365

366

367

368

369

370

371

372

373

374

375

376

377

378

379

380

381

382

383

384

385

386

387

388

389

390

391

392

393

394

395

396

397

398

399

Hui P, Xu X, Xu L, Hui G, Wu S, and Lan Q. 2015. Expression of MMP14 in invasive pituitary adenomas: relationship to invasion and angiogenesis. Int J Clin Exp Pathol 8:3556-3567.

Hulleman E, Quarto M, Vernell R, Masserdotti G, Colli E, Kros JM, Levi D, Gaetani P, Tunici P, Finocchiaro G, Baena RR, Capra M, and Helin K. 2009. A role for the transcription factor HEY1 in glioblastoma. J Cell Mol Med 13:136-146. 10.1111/j.1582-4934.2008.00307.x

Hur H, Lee JY, Yun HJ, Park BW, and Kim MH. 2014. Analysis of HOX gene expression patterns in human breast cancer. Mol Biotechnol 56:64-71. 10.1007/s12033-013-9682-4

Hussain I, Bhan A, Ansari KI, Deb P, Bobzean SA, Perrotti LI, and Mandal SS. 2015. Bisphenol$A$ induces expression of $\mathrm{HOXC6}$, an estrogen-regulated homeobox-containing gene associated with breast cancer. Biochim Biophys Acta 1849:697-708. 10.1016/j.bbagrm.2015.02.003

Ji M, Feng Q, He G, Yang L, Tang W, Lao X, Zhu D, Lin Q, Xu P, Wei Y, and Xu J. 2016. Silencing homeobox C6 inhibits colorectal cancer cell proliferation. Oncotarget 7:2921629227. 10.18632/oncotarget.8703

Kanai M, Hamada J, Takada M, Asano T, Murakawa K, Takahashi Y, Murai T, Tada M, Miyamoto M, Kondo S, and Moriuchi T. 2010. Aberrant expressions of HOX genes in colorectal and hepatocellular carcinomas. Oncol Rep 23:843-851.

Kashyap MK, Marimuthu A, Kishore CJ, Peri S, Keerthikumar S, Prasad TS, Mahmood R, Rao S, Ranganathan P, Sanjeeviah RC, Vijayakumar M, Kumar KV, Montgomery EA, Kumar RV, and Pandey A. 2009. Genomewide mRNA profiling of esophageal squamous cell carcinoma for identification of cancer biomarkers. Cancer Biol Ther 8:36-46.

Kim D, Langmead B, and Salzberg SL. 2015. HISAT: a fast spliced aligner with low memory requirements. Nat Methods 12:357-360. 10.1038/nmeth.3317

Ladam F, and Sagerstrom CG. 2014. Hox regulation of transcription: more complex(es). Dev Dyn 243:4-15. 10.1002/dvdy.23997

Lang F, Perrotti N, and Stournaras C. 2010. Colorectal carcinoma cells--regulation of survival and growth by SGK1. Int J Biochem Cell Biol 42:1571-1575. 10.1016/j.biocel.2010.05.016

Liang X, Lan C, Jiao G, Fu W, Long X, An Y, Wang K, Zhou J, Chen T, Li Y, Xu J, Huang Q, Xu $\mathrm{B}$, and Xiao J. 2017. Therapeutic inhibition of SGK1 suppresses colorectal cancer. Exp Mol Med 49:e399. 10.1038/emm.2017.184

Liao WT, Jiang D, Yuan J, Cui YM, Shi XW, Chen CM, Bian XW, Deng YJ, and Ding YQ. 2011. HOXB7 as a prognostic factor and mediator of colorectal cancer progression. Clin Cancer Res 17:3569-3578. 10.1158/1078-0432.CCR-10-2533

Love MI, Huber W, and Anders S. 2014. Moderated estimation of fold change and dispersion for RNA-seq data with DESeq2. Genome Biol 15:550. 10.1186/s13059-014-0550-8

Luo CL, Liu YQ, Wang P, Song CH, Wang KJ, Dai LP, Zhang JY, and Ye H. 2016. The effect of quercetin nanoparticle on cervical cancer progression by inducing apoptosis, autophagy and anti-proliferation via JAK2 suppression. Biomed Pharmacother 82:595-605. 10.1016/j.biopha.2016.05.029

Malik MF, Satherley LK, Davies EL, Ye L, and Jiang WG. 2016. Expression of Semaphorin 3C in Breast Cancer and its Impact on Adhesion and Invasion of Breast Cancer Cells. Anticancer Res 36:1281-1286.

Man J, Shoemake J, Zhou W, Fang X, Wu Q, Rizzo A, Prayson R, Bao S, Rich JN, and Yu JS. 2014. Sema3C promotes the survival and tumorigenicity of glioma stem cells through Rac1 activation. Cell Rep 9:1812-1826. 10.1016/j.celrep.2014.10.055

Mao L, Yang C, Wang J, Li W, Wen R, Chen J, and Zheng J. 2013. SATB1 is overexpressed in metastatic prostate cancer and promotes prostate cancer cell growth and invasion. $J$ Transl Med 11:111. 10.1186/1479-5876-11-111 
400

401

402

403

404

405

406

407

408

409

410

411

412

413

414

415

416

417

418

419

420

421

422

423

424

425

426

427

428

429

430

431

432

433

434

435

436

437

438

439

440

441

442

443

444

445

446

447

448

449

450
Moroz A, Delella FK, Lacorte LM, Deffune E, and Felisbino SL. 2013. Fibronectin induces MMP2 expression in human prostate cancer cells. Biochem Biophys Res Commun 430:1319-1321. 10.1016/j.bbrc.2012.12.031

Qian P, Zuo Z, Wu Z, Meng X, Li G, Wu Z, Zhang W, Tan S, Pandey V, Yao Y, Wang P, Zhao L, Wang J, Wu Q, Song E, Lobie PE, Yin Z, and Zhu T. 2011. Pivotal role of reduced let$7 \mathrm{~g}$ expression in breast cancer invasion and metastasis. Cancer Res 71:6463-6474. 10.1158/0008-5472.CAN-11-1322

Ramachandran S, Liu P, Young AN, Yin-Goen Q, Lim SD, Laycock N, Amin MB, Carney JK, Marshall FF, Petros JA, and Moreno CS. 2005. Loss of HOXC6 expression induces apoptosis in prostate cancer cells. Oncogene 24:188-198. 10.1038/sj.onc.1207906

Riihila PM, Nissinen LM, Ala-Aho R, Kallajoki M, Grenman R, Meri S, Peltonen S, Peltonen J, and Kahari VM. 2014. Complement factor $\mathrm{H}$ : a biomarker for progression of cutaneous squamous cell carcinoma. J Invest Dermatol 134:498-506. 10.1038/jid.2013.346

Seder CW, Hartojo W, Lin L, Silvers AL, Wang Z, Thomas DG, Giordano TJ, Chen G, Chang AC, Orringer MB, and Beer DG. 2009a. INHBA overexpression promotes cell proliferation and may be epigenetically regulated in esophageal adenocarcinoma. $J$ Thorac Oncol 4:455-462. 10.1097/JTO.0b013e31819c791a

Seder CW, Hartojo W, Lin L, Silvers AL, Wang Z, Thomas DG, Giordano TJ, Chen G, Chang AC, Orringer MB, and Beer DG. 2009b. Upregulated INHBA expression may promote cell proliferation and is associated with poor survival in lung adenocarcinoma. Neoplasia 11:388-396.

Senft C, Priester M, Polacin M, Schroder K, Seifert V, Kogel D, and Weissenberger J. 2011. Inhibition of the JAK-2/STAT3 signaling pathway impedes the migratory and invasive potential of human glioblastoma cells. J Neurooncol 101:393-403. 10.1007/s11060-0100273-y

Seol HS, Lee SE, Song JS, Rhee JK, Singh SR, Chang S, and Jang SJ. 2016. Complement proteins $\mathrm{C} 7$ and $\mathrm{CFH}$ control the stemness of liver cancer cells via LSF-1. Cancer Lett 372:24-35. 10.1016/j.canlet.2015.12.005

Shaoqiang C, Yue Z, Yang L, Hong Z, Lina Z, Da P, and Qingyuan Z. 2013. Expression of HOXD3 correlates with shorter survival in patients with invasive breast cancer. Clin Exp Metastasis 30:155-163. 10.1007/s10585-012-9524-y

Sponziello M, Rosignolo F, Celano M, Maggisano V, Pecce V, De Rose RF, Lombardo GE, Durante C, Filetti S, Damante G, Russo D, and Bulotta S. 2016. Fibronectin-1 expression is increased in aggressive thyroid cancer and favors the migration and invasion of cancer cells. Mol Cell Endocrinol 431:123-132. 10.1016/j.mce.2016.05.007

Sui CJ, Xu F, Shen WF, Dai BH, Lu JJ, Zhang MF, and Yang JM. 2016. MicroRNA-147 suppresses human hepatocellular carcinoma proliferation migration and chemosensitivity by inhibiting HOXC6. Am J Cancer Res 6:2787-2798.

Tait DL, Bahrani-Mostafavi Z, Vestal CG, Richardson C, and Mostafavi MT. 2015. Downregulation of HOXC6 in Serous Ovarian Cancer. Cancer Invest 33:303-311. 10.3109/07357907.2015.1041641

Tsuru A, Setoguchi T, Matsunoshita Y, Nagao-Kitamoto H, Nagano S, Yokouchi M, Maeda S, Ishidou Y, Yamamoto T, and Komiya S. 2015. Hairy/enhancer-of-split related with YRPW motif protein 1 promotes osteosarcoma metastasis via matrix metallopeptidase 9 expression. Br J Cancer 112:1232-1240. 10.1038/bjc.2015.84

Ulasov I, Yi R, Guo D, Sarvaiya P, and Cobbs C. 2014. The emerging role of MMP14 in brain tumorigenesis and future therapeutics. Biochim Biophys Acta 1846:113-120. 10.1016/j.bbcan.2014.03.002

Vaz J, Ansari D, Sasor A, and Andersson R. 2015. SPARC: A Potential Prognostic and Therapeutic Target in Pancreatic Cancer. Pancreas 44:1024-1035. 10.1097/MPA.0000000000000409 
451

452

453

454

455

456

457

458

459

460

461

462

463

464

465

466

467

468

469

470

471

472

473

474

475

476

477

478

479

480

481

482

483

484

485

486

487

488
Wang YP, Huang LY, Sun WM, Zhang ZZ, Fang JZ, Wei BF, Wu BH, and Han ZG. 2013. Insulin receptor tyrosine kinase substrate activates EGFR/ERK signalling pathway and promotes cell proliferation of hepatocellular carcinoma. Cancer Lett 337:96-106. 10.1016/j.canlet.2013.05.019

Xu X, Zhao Z, Guo S, Li J, Liu S, You Y, Ni B, Wang H, and Bie P. 2017. Increased semaphorin $3 \mathrm{c}$ expression promotes tumor growth and metastasis in pancreatic ductal adenocarcinoma by activating the ERK1/2 signaling pathway. Cancer Lett 397:12-22. 10.1016/j.canlet.2017.03.014

Yan T, Lin Z, Jiang J, Lu S, Chen M, Que H, He X, Que G, Mao J, Xiao J, and Zheng Q. 2015. MMP14 regulates cell migration and invasion through epithelial-mesenchymal transition in nasopharyngeal carcinoma. Am J Transl Res 7:950-958.

Yang MH, Hu ZY, Xu C, Xie LY, Wang XY, Chen SY, and Li ZG. 2015. MALAT1 promotes colorectal cancer cell proliferation/migration/invasion via PRKA kinase anchor protein 9. Biochim Biophys Acta 1852:166-174. 10.1016/j.bbadis.2014.11.013

Yin J, Chen G, Liu Y, Liu S, Wang P, Wan Y, Wang X, Zhu J, and Gao H. 2010. Downregulation of SPARC expression decreases gastric cancer cellular invasion and survival. $J$ Exp Clin Cancer Res 29:59. 10.1186/1756-9966-29-59

Yu G, Wang LG, Han Y, and He QY. 2012. clusterProfiler: an R package for comparing biological themes among gene clusters. OMICS 16:284-287. 10.1089/omi.2011.0118

Yuan G, Regel I, Lian F, Friedrich T, Hitkova I, Hofheinz RD, Strobel P, Langer R, Keller G, Rocken C, Zimmermann W, Schmid RM, Ebert MP, and Burgermeister E. 2013. WNT6 is a novel target gene of caveolin-1 promoting chemoresistance to epirubicin in human gastric cancer cells. Oncogene 32:375-387. 10.1038/onc.2012.40

Zarrabi K, Dufour A, Li J, Kuscu C, Pulkoski-Gross A, Zhi J, Hu Y, Sampson NS, Zucker S, and Cao J. 2011. Inhibition of matrix metalloproteinase 14 (MMP-14)-mediated cancer cell migration. J Biol Chem 286:33167-33177. 10.1074/jbc.M111.256644

Zhang H, Sun Z, Li Y, Fan D, and Jiang H. 2017. MicroRNA-200c binding to FN1 suppresses the proliferation, migration and invasion of gastric cancer cells. Biomed Pharmacother 88:285-292. 10.1016/j.biopha.2017.01.023

Zhang Q, Jin XS, Yang ZY, Wei M, Liu BY, and Gu QL. 2013. Upregulated Hoxc6 expression is associated with poor survival in gastric cancer patients. Neoplasma 60:439-445. 10.4149/neo_2013_057

Zhang Y. 2013. Epidemiology of esophageal cancer. World J Gastroenterol 19:5598-5606. 10.3748/wjg.v19.i34.5598

Zheng XL, and Yu HG. 2018. Wnt6 contributes tumorigenesis and development of colon cancer via its effects on cell proliferation, apoptosis, cell-cycle and migration. Oncol Lett 16:1163-1172. 10.3892/ol.2018.8729 
Table $\mathbf{1}$ (on next page)

The primer sequences for qRT-PCR 


\begin{tabular}{|c|c|c|}
\hline & Forward & Reverse \\
\hline HOXC6 & ACAGACCTCAATCGCTCAGGA & AGGGGTAAATCTGGATACTGGC \\
\hline MMP14 & CGAGGTGCCCTATGCCTAC & CTCGGCAGAGTCAAAGTGG \\
\hline SPARC & AGCACCCCATTGACGGGTA & GGTCACAGGTCTCGAAAAAGC \\
\hline FN1 & CGGTGGCTGTCAGTCAAAG & AAACCTCGGCTTCCTCCATAA \\
\hline INHBA & CAACAGGACCAGGACCAAAGT & GAGAGCAACAGTTCACTCCTC \\
\hline SEMA3C & TAACCAAGAGGAATGCGGTCA & TGCTCCTGTTATTGTCAGTCAGT \\
\hline HEY1 & ATCTGCTAAGCTAGAAAAAGCCG & GTGCGCGTCAAAGTAACCT \\
\hline SGK1 & GCAGAAGAAGTGTTCTATGCAGT & CCGCTCCGACATAATATGCTT \\
\hline SMAD9 & CTGTGCTCGTGCCAAGACA & TGGAAAGAGTCAGGATAGGTGG \\
\hline WNT6 & GGTGCGAGAGTGCCAGTTC & CGTCTCCCGAATGTCCTGTT \\
\hline BRCA2 & CACCCACCCTTAGTTCTACTGT & CCAATGTGGTCTTTGCAGCTAT \\
\hline SAMD9 & GCAACCATCCATAGACCTGAC & AATAGTGCCATTGGTACGTGAAT \\
\hline AKAP9 & CACGGCATAAGGGAGAAATGG & GCTGTCTCTGTAGAGCACACT \\
\hline SATB1 & CCAGGTTGGAAAGTGGAATCC & GGGGCAACTGTGTAACTGAAT \\
\hline CFH & GTGAAGTGTTTACCAGTGACAGC & AACCGTACTGCTTGTCCAAAA \\
\hline JAK2 & TCTGGGGAGTATGTTGCAGAA & AGACATGGTTGGGTGGATACC \\
\hline MCTP1 & AGTTTACGCCTATCAGACCTACA & GATCGCTCAACCCGTTGGAAT \\
\hline ANXA10 & GCTGGCCTCATGTACCCAC & CAAGCAGTAGGCTTCTCGC \\
\hline DAPP1 & CAGCCTTTGATTGGAAGCGAG & TGTGAACCCGGACAGATTCAT \\
\hline GAPDH & СТСТGACTTCAACAGCGACACC & CTGTTGCTGTAGCCAAATTCGTT \\
\hline
\end{tabular}


Table 2 (on next page)

The primer sequences for PCR amplification 


\begin{tabular}{lll} 
Gene fragment & Primer sequence $\left(\mathbf{5}^{\prime}-\mathbf{3}^{\prime}\right)$ \\
\hline PCDH-CMV-MCS-EF1 Forward & GCGTGGATATCTAAGTCGACAATCAACCTCTGG \\
& Reverse & AATATCTCGAGGGTGGCGTCTAGCGTAGGCG \\
genemycin & Forward & GTCTACTCGAGGCCACCATGATTGAACAAGATGGATTGCAC \\
resistance gene & & \\
& Reverse & GCTATGATATCTCAGAAGAACTCGTCAAGAAGGC \\
HOXC6 & Forward & CCCGGTCTAGAGCCACCATGAATTCCTACTTCACTAACCCTTCC \\
& Reverse & TTGGCGGATCCTCACTCTTTCTGCTTCTCCTCTTC
\end{tabular}

1 
Table 3(on next page)

List of genes regulated by HOXC6 in Eca109 and TE10 stable cells 


\begin{tabular}{|c|c|c|c|c|}
\hline \multicolumn{2}{|c|}{ Gene } & \multirow{2}{*}{$\begin{array}{c}\text { Description of function } \\
\text { promote cell migration and } \\
\text { invasion }\end{array}$} & \multirow{2}{*}{$\begin{array}{c}\text { Cancer type } \\
\text { nasopharyngeal }\end{array}$} & \multirow{2}{*}{$\begin{array}{c}\text { Reference } \\
\text { (Yan et al. 2015) }\end{array}$} \\
\hline Eca109-up & MMP14 & & & \\
\hline & & $\begin{array}{l}\text { promote tumor invasion and } \\
\text { angiogenesis }\end{array}$ & $\begin{array}{l}\text { pituitary } \\
\text { adenomas }\end{array}$ & (Hui et al. 2015) \\
\hline & SATB1 & $\begin{array}{l}\text { promote cell growth and } \\
\text { invasion }\end{array}$ & pancreatic cancer & (Chen et al. 2015) \\
\hline & & $\begin{array}{l}\text { promote cell growth and } \\
\text { invasion }\end{array}$ & prostate cancer & (Mao et al. 2013) \\
\hline & & $\begin{array}{l}\text { promote cell invasion and } \\
\text { metastasis }\end{array}$ & breast cancer & (Han et al. 2008) \\
\hline & AKAP9 & $\begin{array}{l}\text { promote proliferation, migration } \\
\text { and invasion }\end{array}$ & colorectal cancer & (Yang et al. 2015) \\
\hline & & $\begin{array}{c}\text { promote proliferation, migration } \\
\text { and invasion }\end{array}$ & colorectal cancer & (Hu et al. 2016) \\
\hline & $\mathrm{CFH}$ & $\begin{array}{l}\text { promote proliferation and } \\
\text { migration }\end{array}$ & $\begin{array}{c}\text { cutaneous } \\
\text { squamous cell } \\
\text { carcinoma }\end{array}$ & (Riihila et al. 2014) \\
\hline & & promote tumorsphere formation & liver cancer & (Seol et al. 2016) \\
\hline & JAK2 & $\begin{array}{c}\text { JAK2 inhibition prevents cell } \\
\text { migration and invasion }\end{array}$ & glioblastoma & (Senft et al. 2011) \\
\hline & & $\begin{array}{l}\text { JAK2 inhibition suppresses cell } \\
\text { migration, invasion and } \\
\text { proliferation }\end{array}$ & cervical cancer & (Luo et al. 2016) \\
\hline TE10-up & SPARC & $\begin{array}{l}\text { promote cell invasion and } \\
\text { growth }\end{array}$ & gastric cancer & (Yin et al. 2010) \\
\hline
\end{tabular}




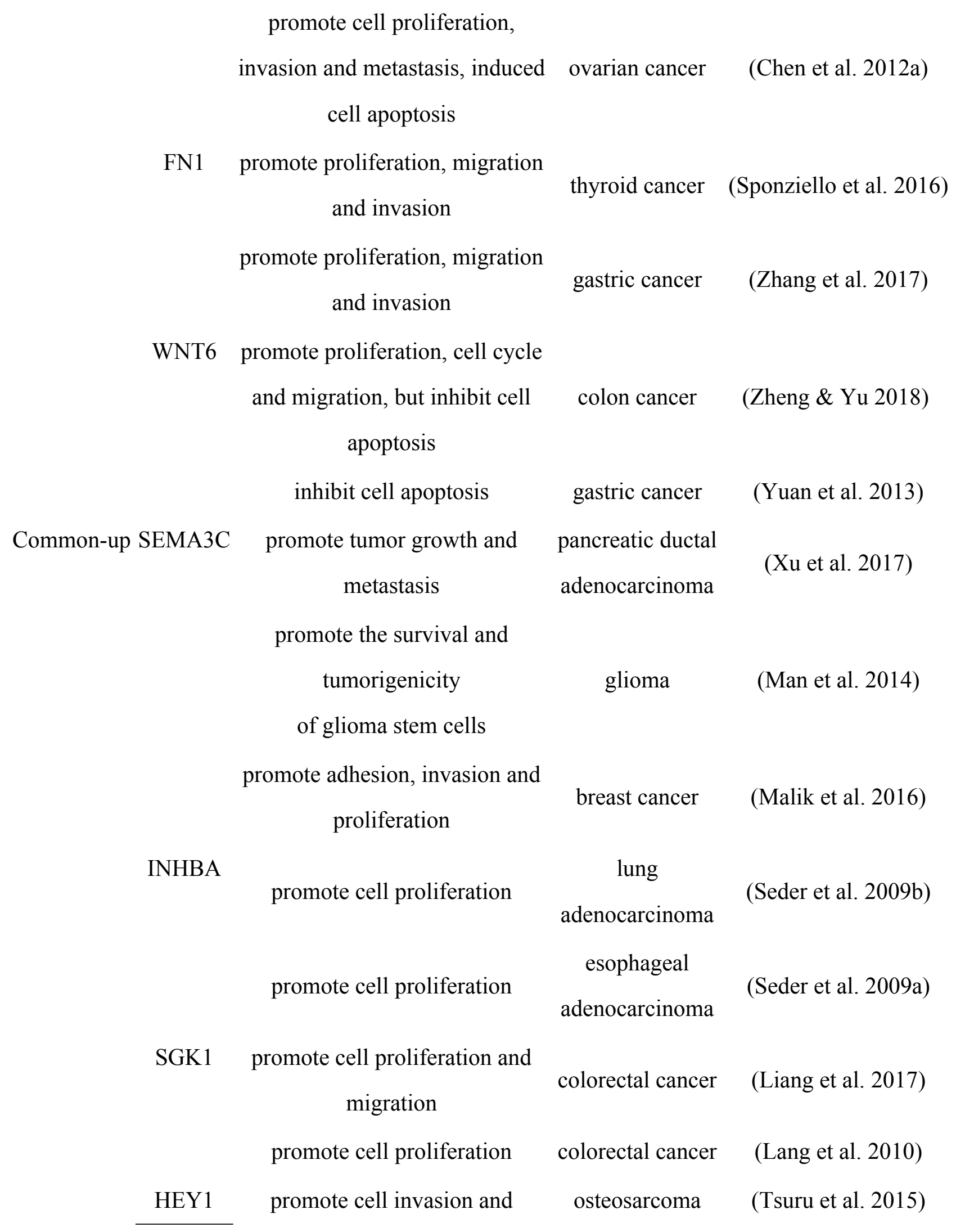


metastasis

1 


\section{Figure 1}

HOXC6 is highly expressed in many cancer types.

Microarray data retrieved from Gene Expression Omnibus (GEO) repository were utilized to analyze HOXC6 expression at mRNA level in various cancers including (A) lung cancer, (B) colorectal cancer, (C) prostate cancer, (D) soft-tissue sarcoma, (E) renal carcinoma, (F) gastric cancer and (G-I) ESCC. 

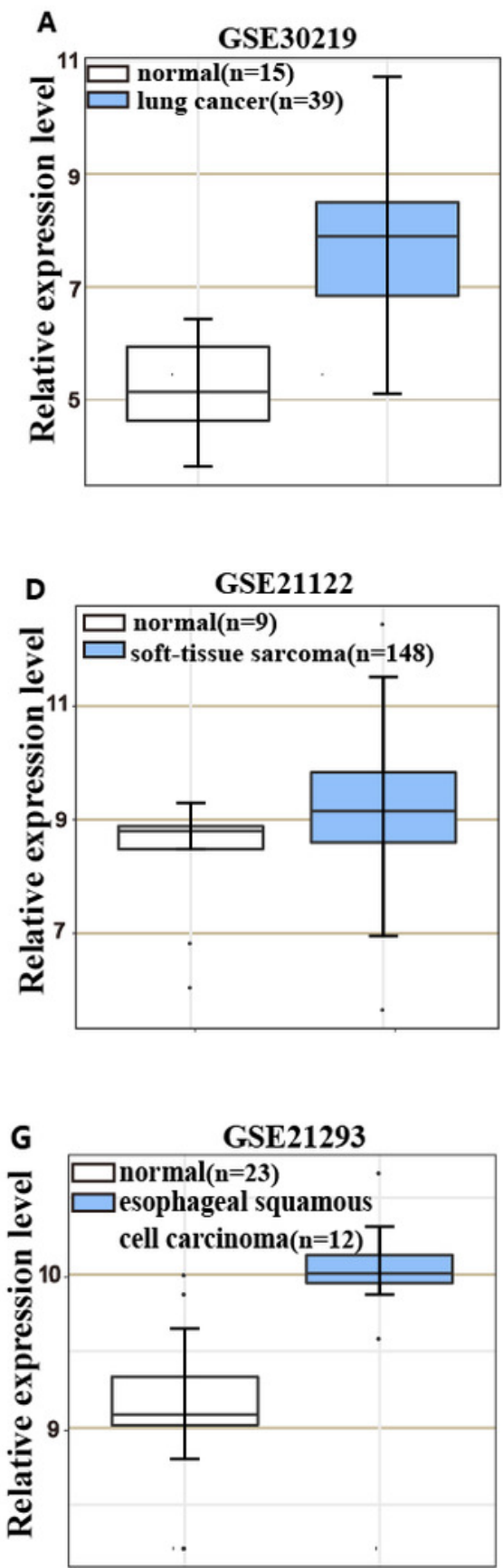

\section{B}

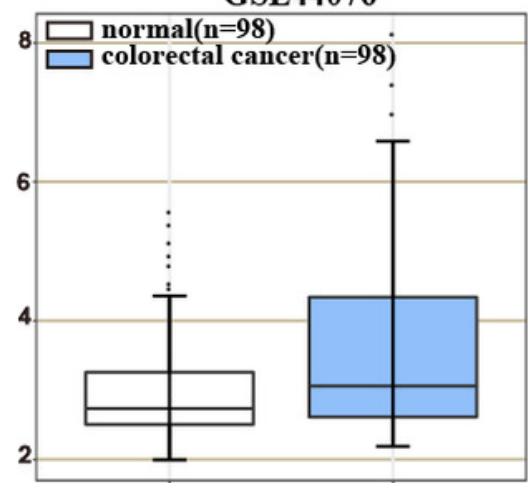

GSE44076
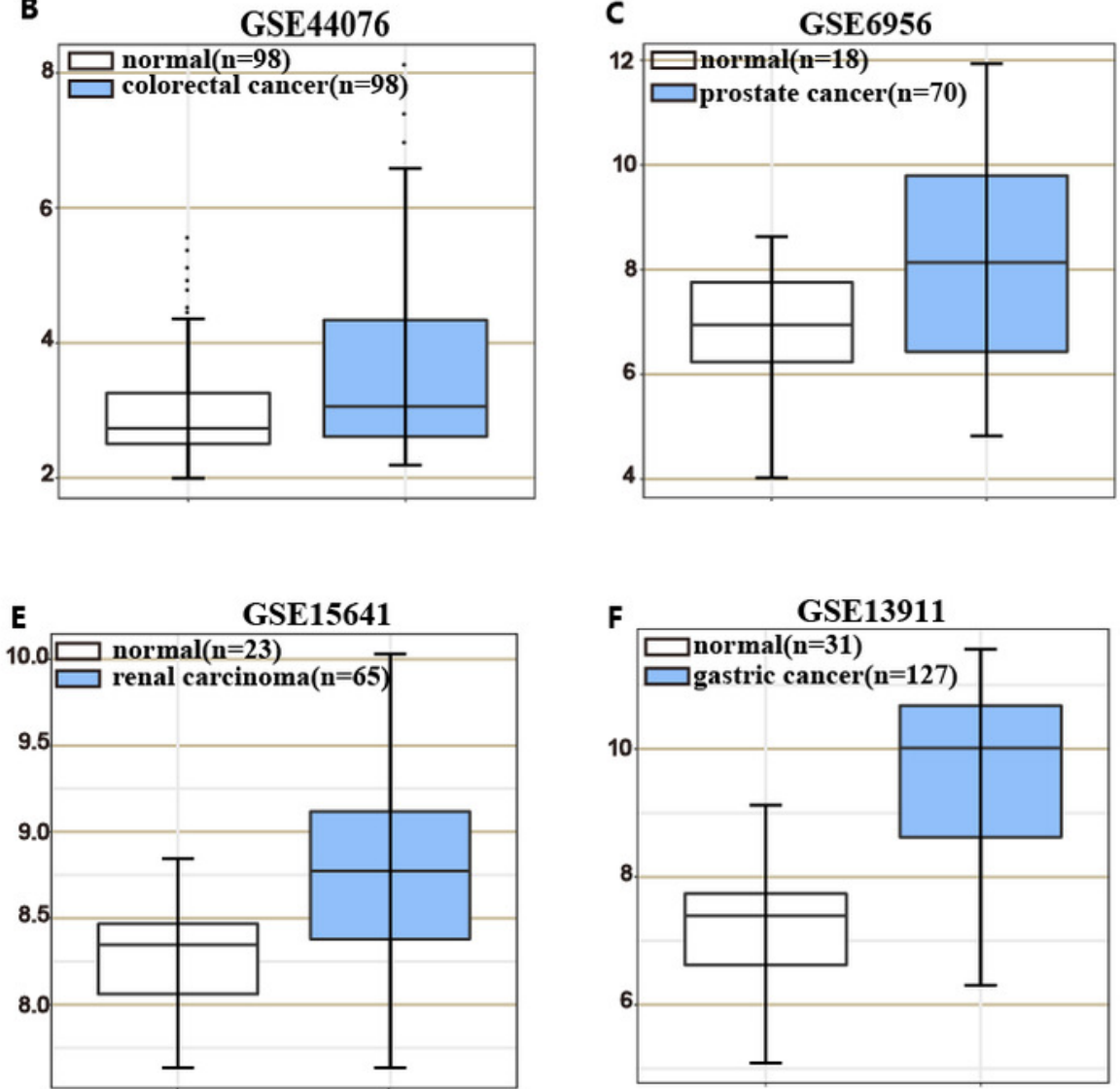

H

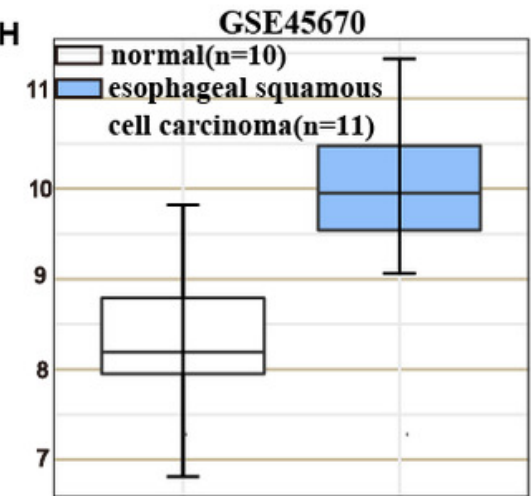

GSE13911

GSE23400

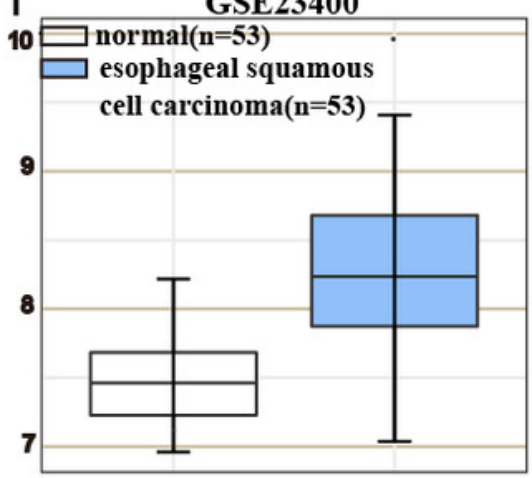

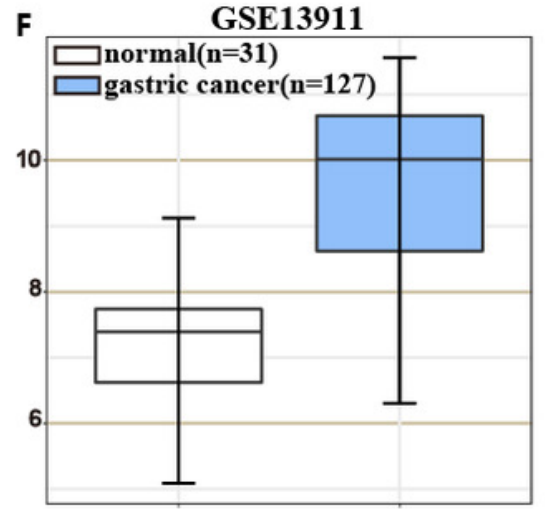




\section{Figure 2}

HOXC6 was highly expressed in ESCC tumor tissues.

(A) Representative images and (B) IHC score of HOXC6 from immunohistochemical analysis.

(C) Relative HOXC6 mRNA expression levels in tumor tissues compared with normal tissues as measured by qRT-PCR. Each of the columns in the bar graph represents the value of one tumor sample as compared with that of its normal control. The expression of GAPDH was used as the internal control. HOXC6 mRNA expression level was evaluated using the $2^{-\Delta \Delta c t}$ method. All specimens $(n=32)$ were examined in triplicate. (D) Representative images of western blot, $\beta$-actin has been used as an internal control. (E) The quantification of the relative expression level of HOXC6 as determined by normalized gray values. ${ }^{* *} p<0.01 ; * * * p$ $<0.001$.
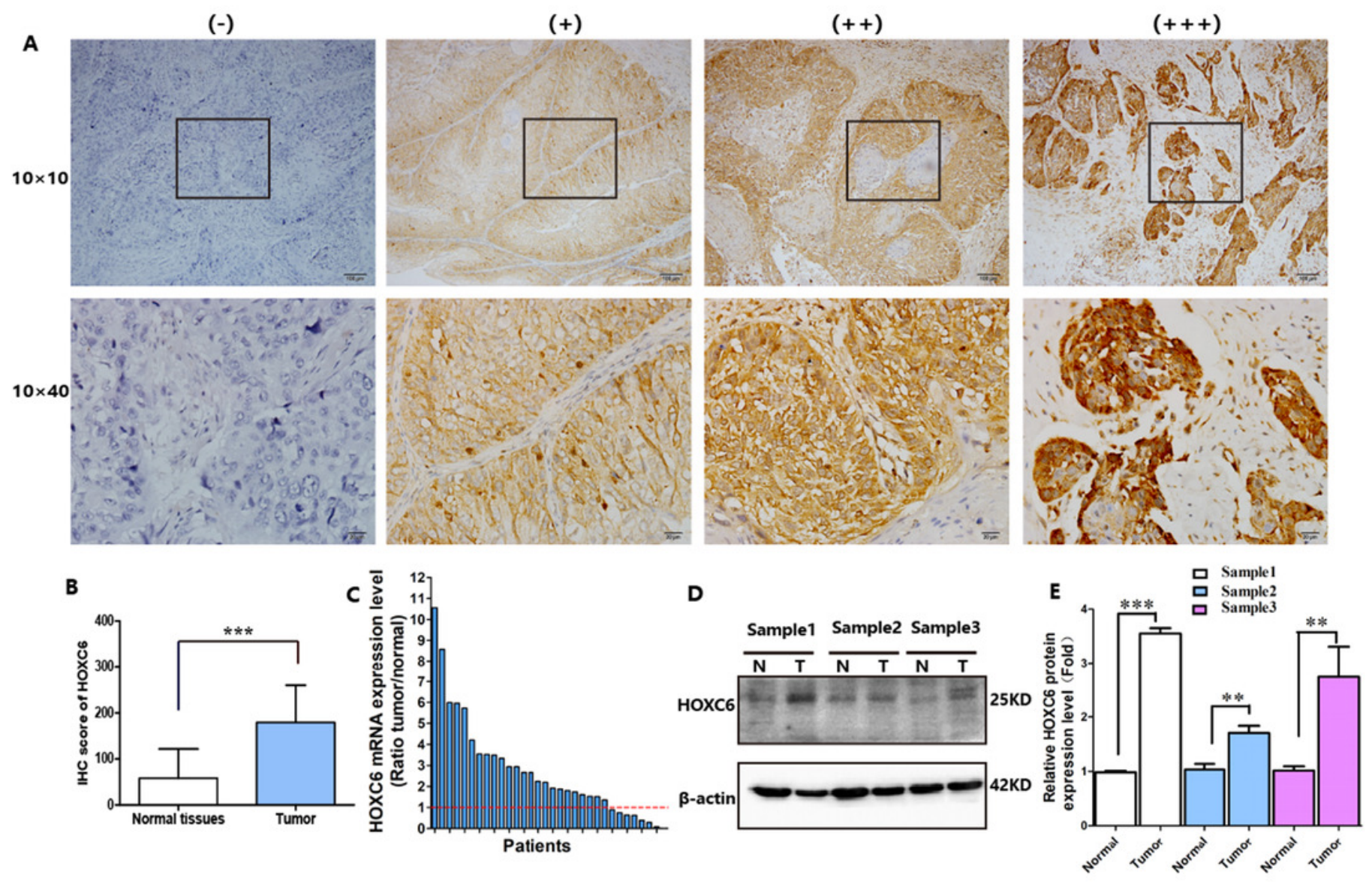


\section{Figure 3}

Lentiviral vector and verification of HOXC6 overexpression.

(A) The recombinant lentiviral vector pCDH-HOXC6. (B) The quantification of relative HOXC6 mRNA expression levels as measured by qRT-PCR. GAPDH has been used as the internal control. (C) The result of western blot and (D) the quantification of relative HOXC6 protein expression levels as determined by the normalized gray values. $\beta$-actin has been used as an internal control.** $p<0.01 ;{ }^{* * *} p<0.001$.
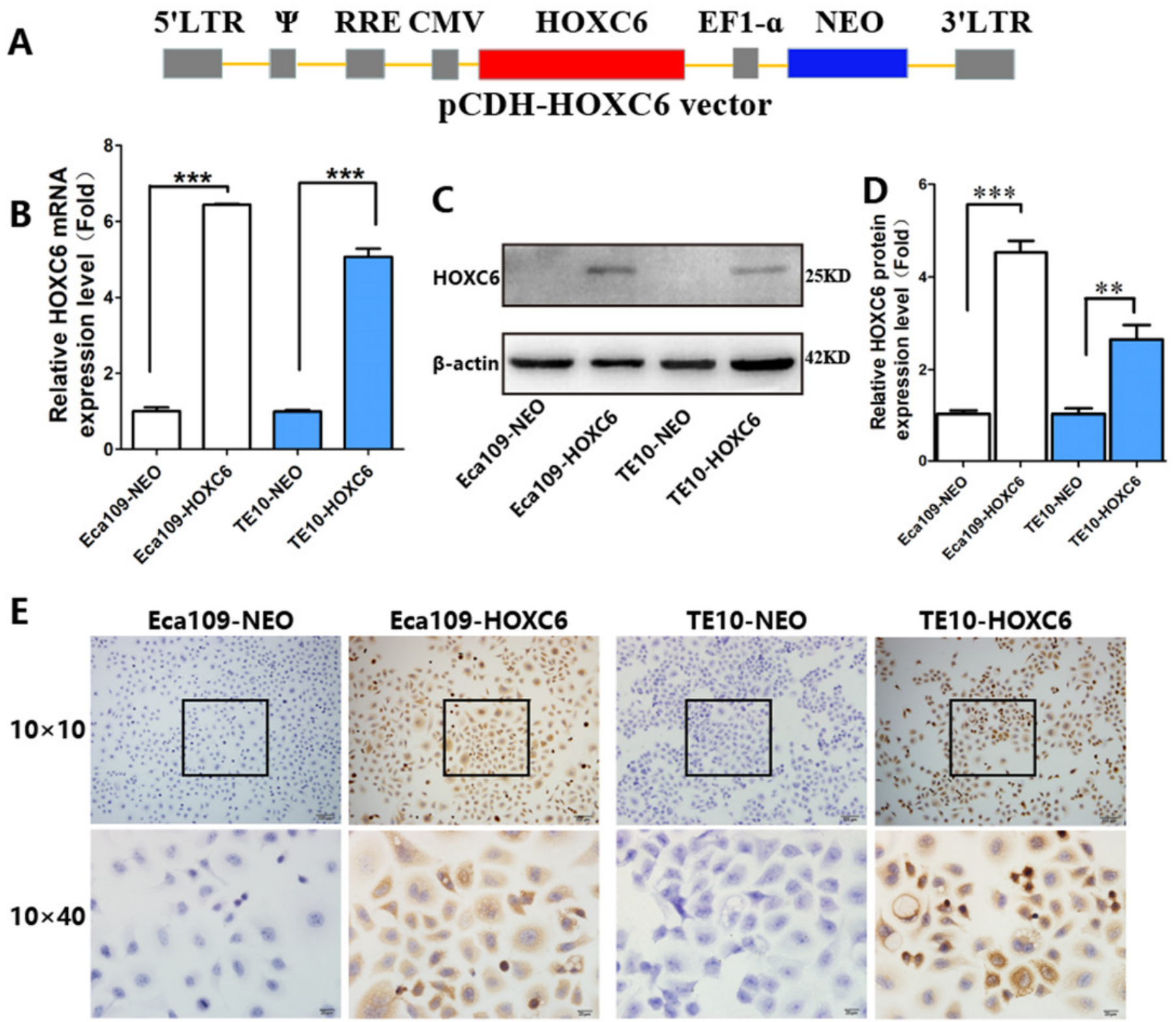


\section{Figure 4}

HOXC6 promoted ESCC cell migration.

Wound healing assay was performed to evaluate the migration of stably infected cells.

Representative images from the wound healing assay in (A) Eca109 and (B) TE10 stable cells.

(C)The wound healing width of Eca109-HOXC6 was significantly wider than in the Eca109-

NEO cells. Similarly, (D) the effect of HOXC6 expression on the ability of wound healing of the two ESCC cell lines. There were at least 12 replicates included for each cell line. These data demonstrated that HOXC6 promoted ESCC cell migration. $* * * p<0.001$.

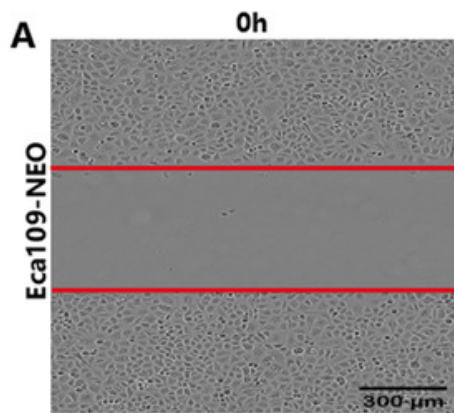

$18 \mathrm{~h}$
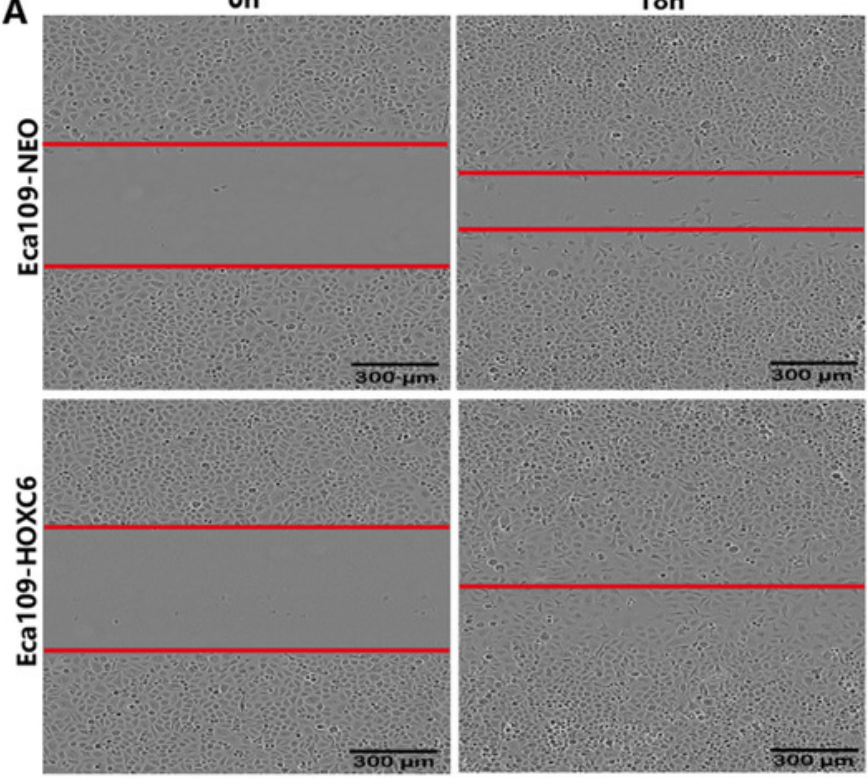

C

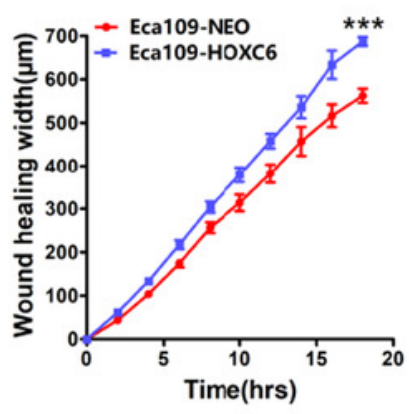

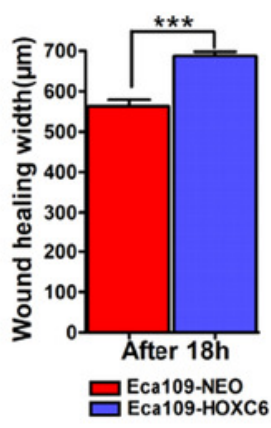
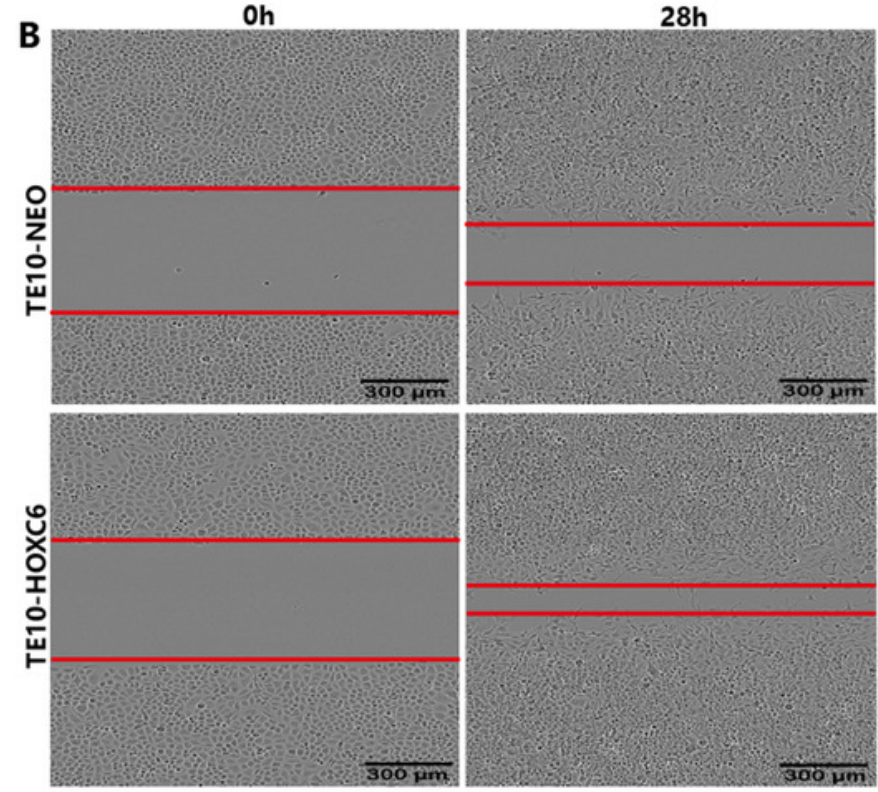

D
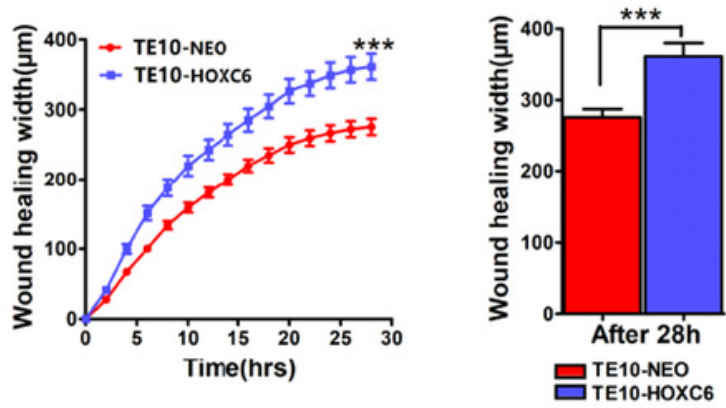


\section{Figure 5}

HOXC6 promoted ESCC cell invasion.

Matrigel invasion assay was used to assess cell invasion capacity. Representative images from the Matrigel invasion assay in (A) Eca109 and (B) TE10 stable cells. By calculating the invasion width, the invasion capacity of (C) Eca109-HOXC6 and (D) TE10-HOXC6 cells was greater than the controls. These data demonstrate that HOXC6 effectively promoted ESCC cell invasion. ${ }^{*} p<0.05 ;{ }^{* *} p<0.01$.
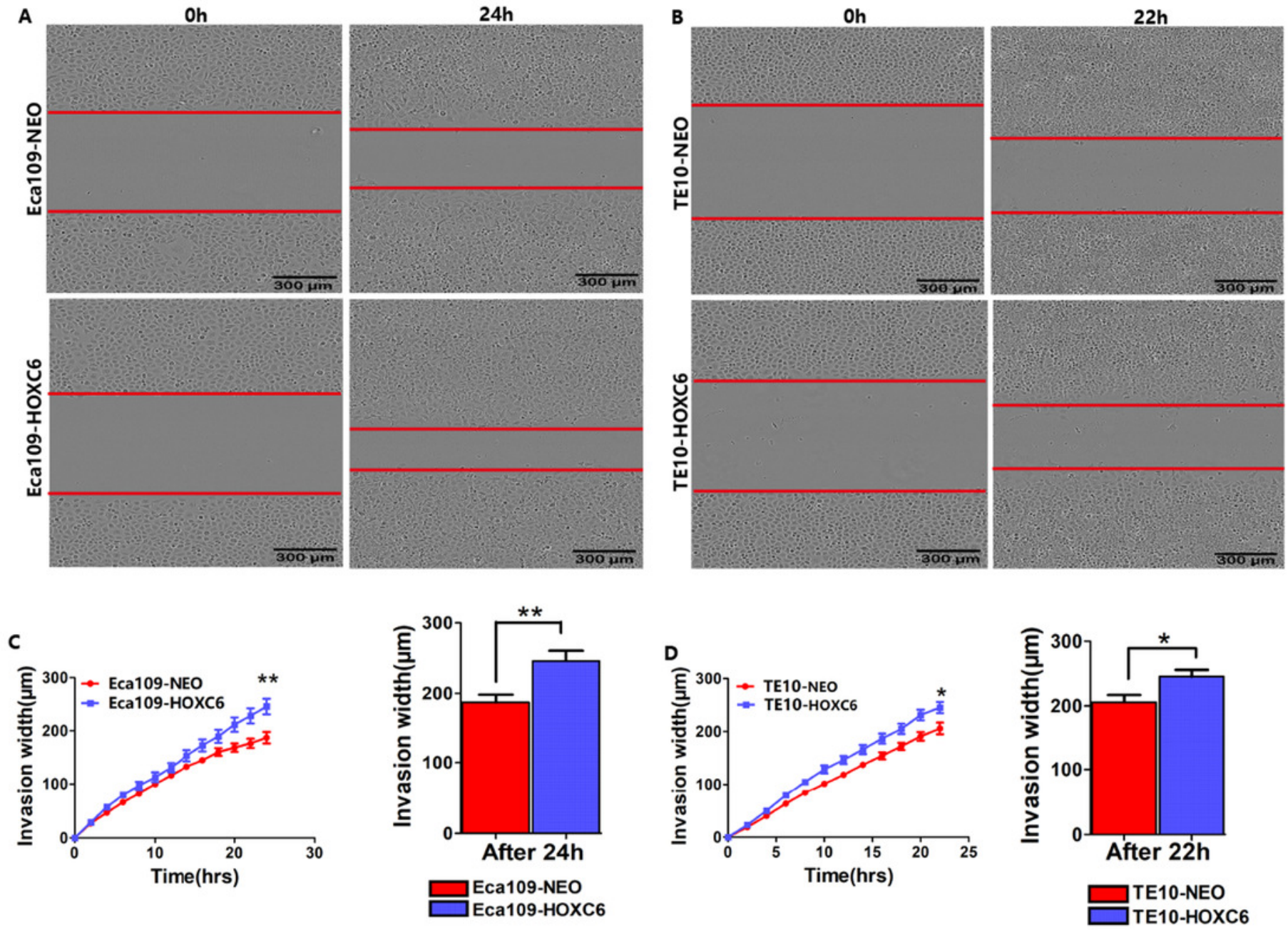


\section{Figure 6}

HOXC6 promoted ESCC cell proliferation.

Growth curves were constructed via real-time monitoring. (A) The growth curve of Eca109HOXC6 and Eca109-NEO cell lines. (B)The growth curve of TE10-HOXC6 and TE10-NEO cell lines. (C-D) The growth curves as determined by OD450 values using CCK8 kit and (E-F) colony formation assay was also used to evaluate the colony formation ability of these cell lines. CCK8 and colony formation assays were conducted in triplicate.Overall, these data suggest that HOXC6 promoted ESCC cell proliferation. ${ }^{*} p<0.05$; **p $<0.01$; **p $<0.001$. 
A

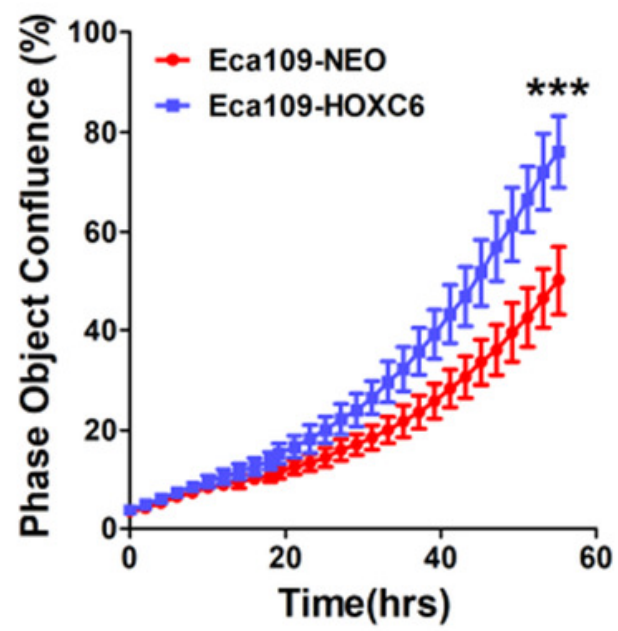

C

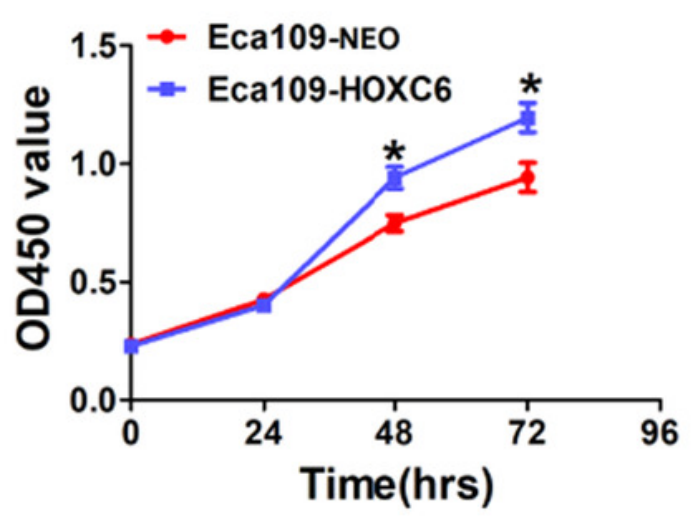

$\mathbf{E}$
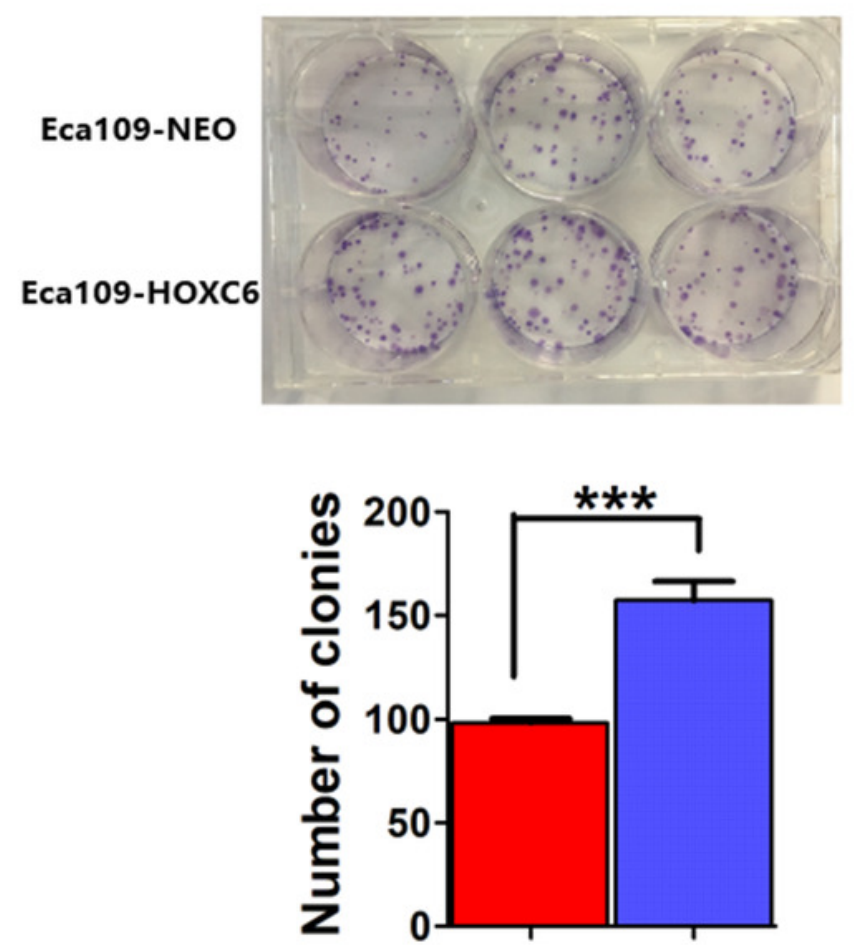

Eca109-NEO Eca109-HOXC6

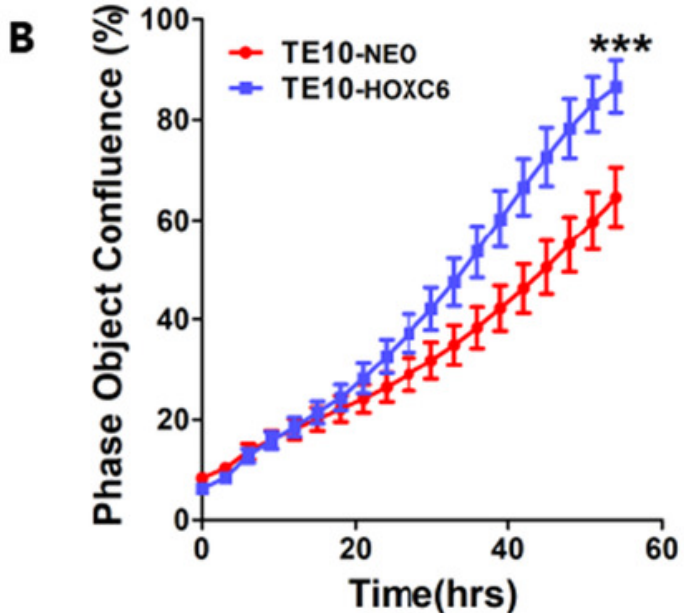

D

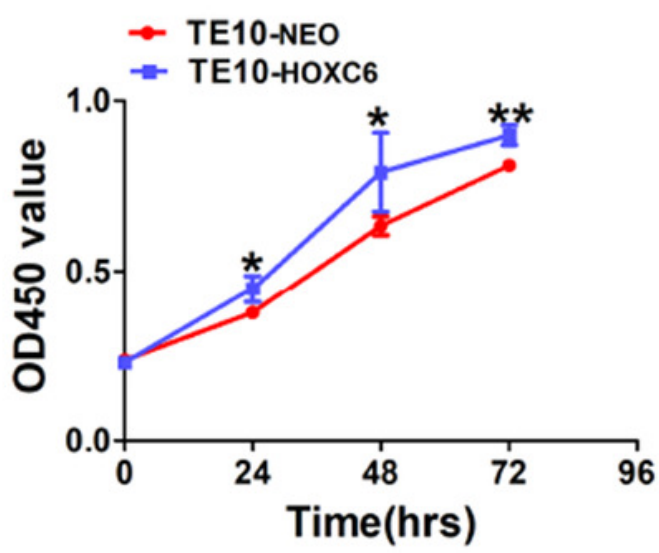

$\mathbf{F}$

TE10-NEO

TE10-HOXC6
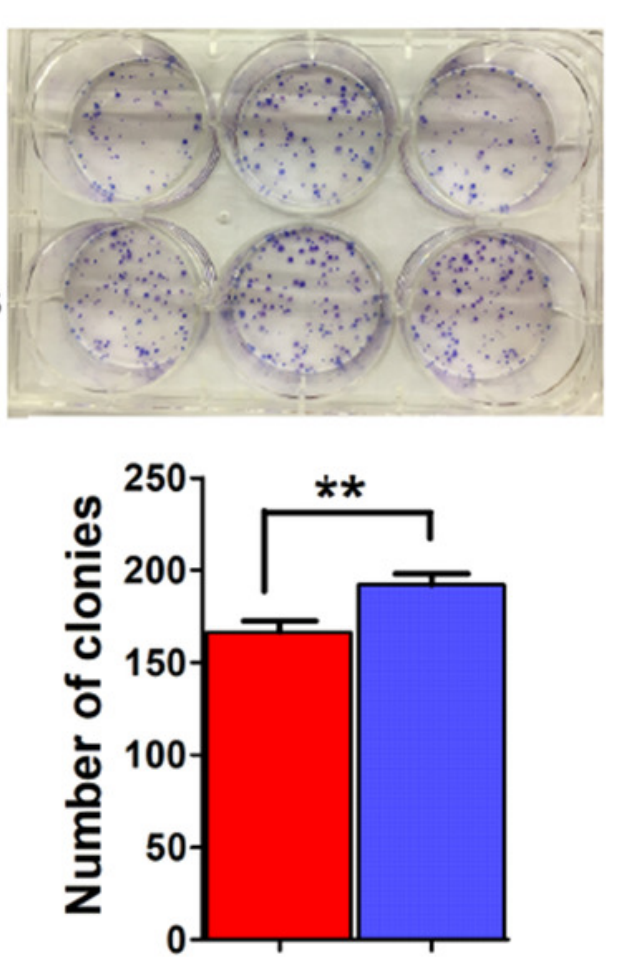

TE10-NEO

TE10-HOXC6 


\section{Figure 7}

RNA-seq analysis of the interactive genes of HOXC6 in Eca109 and TE10 stable cells.

(A) The volcano diagrams show the global changes in mRNA expression patterns for Eca109 and TE10 stable cells. (B- C) The Venn diagrams show the common up-regulated genes and down-regulated genes and the conmmon regulted genes are also shown in the table. (D-E) The relative expression of genes regulated by HOXC6 at the mRNA level were identified by qRT-PCR. (F-G) GO analysis showed various functional groups of genes regulated by HOXC6 and $(\mathrm{H}-\mathrm{I})$ KEGG pathway analysis showed functional pathways for Eca109 and TE10 stable cells.
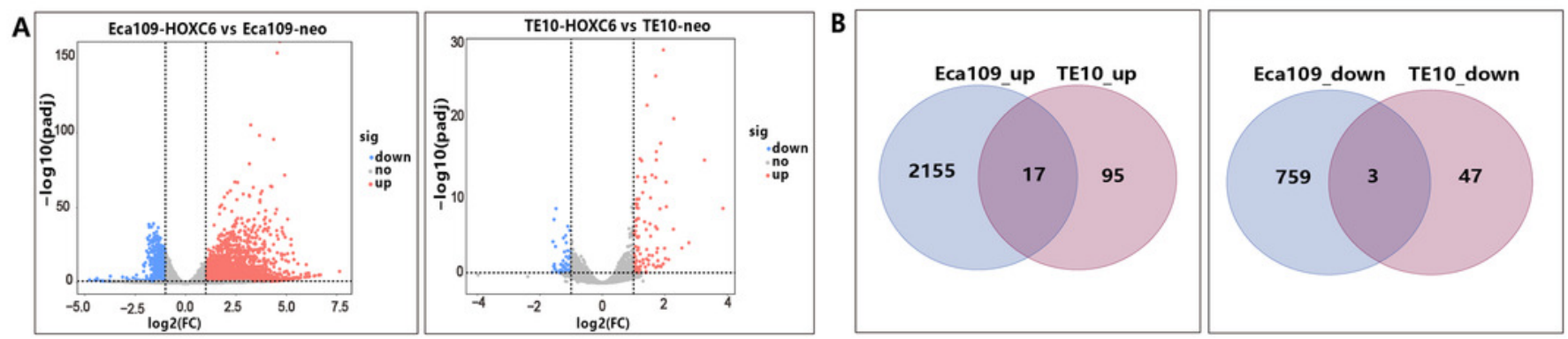

C
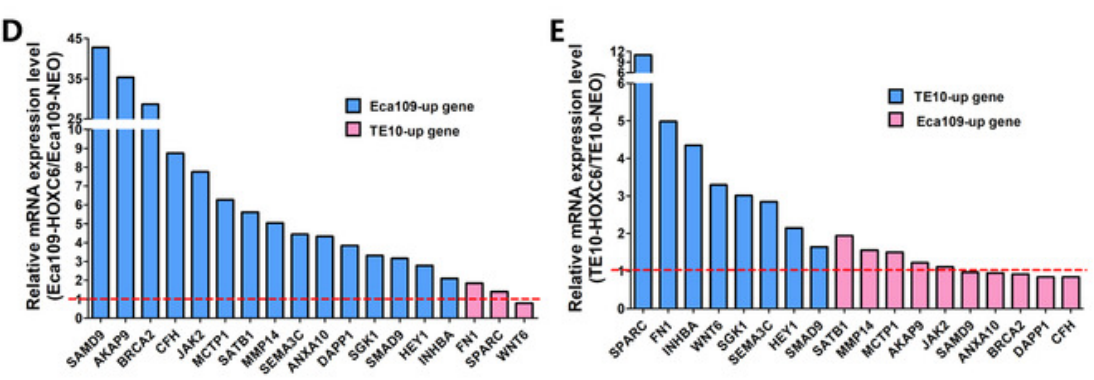

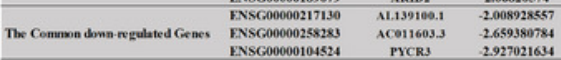

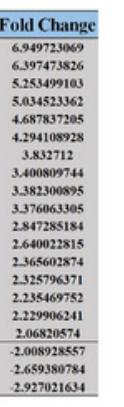

$\mathbf{F}$
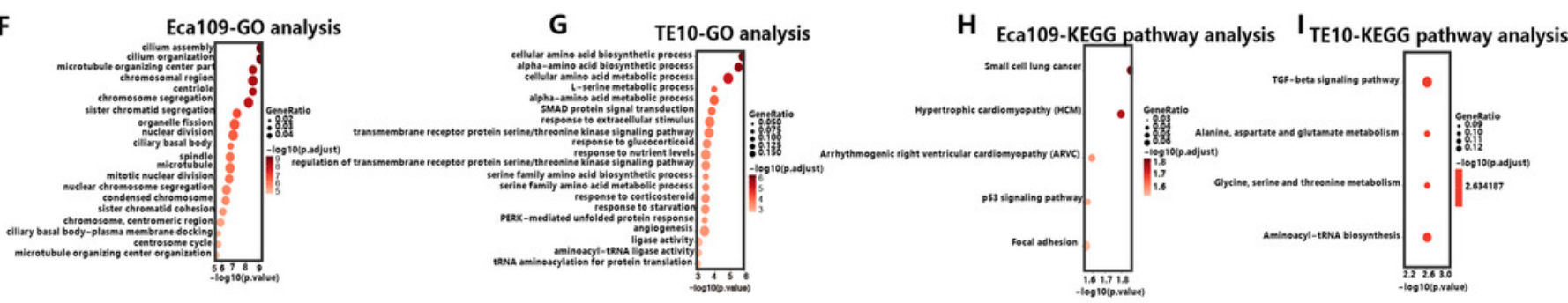
Figure 8

Gene expression omnibus database analysis.

Many genes regulated by HOXC6 in ESCC such as MMP14, SPARC, and FN1 were highly expressed in ESCC.
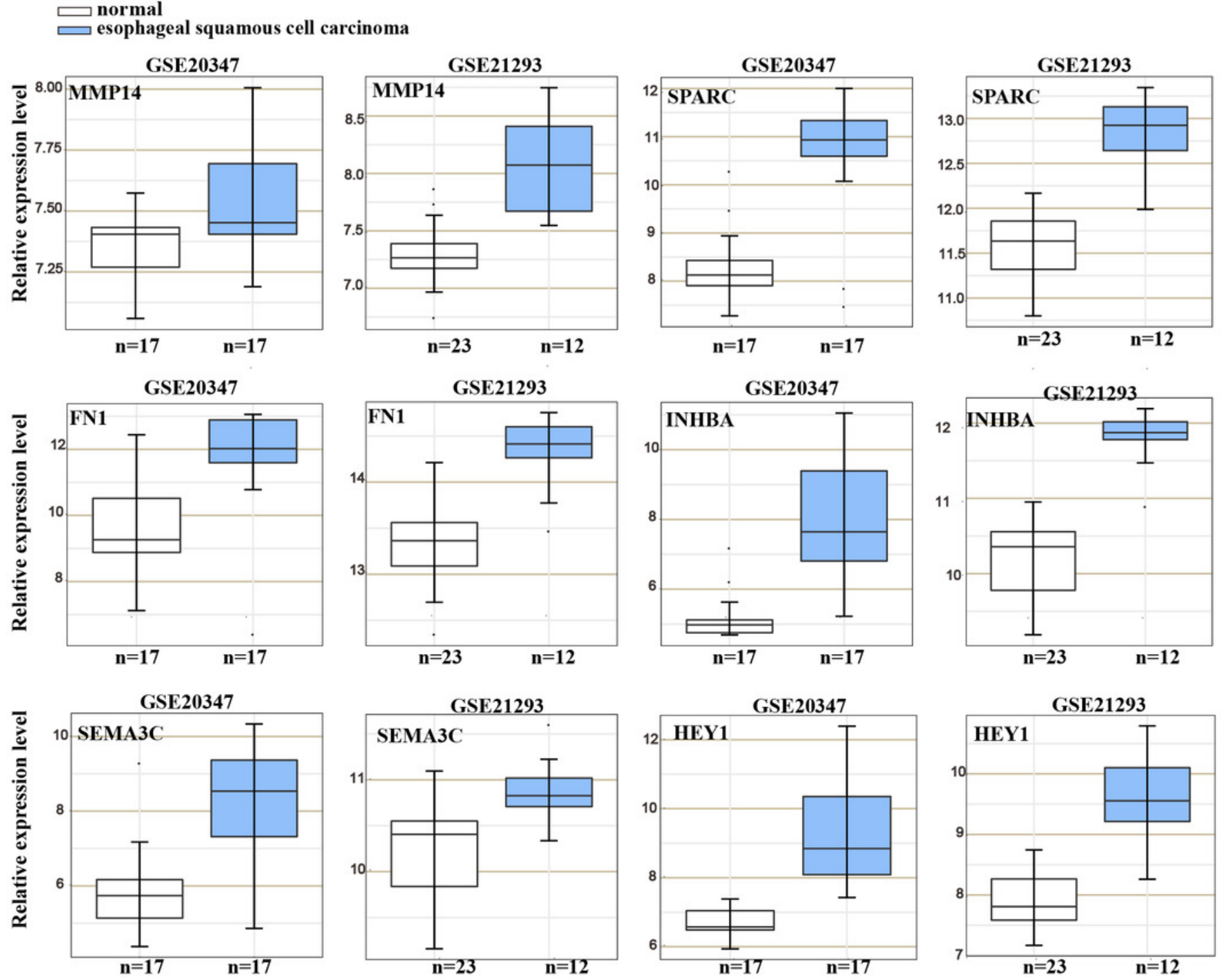